\title{
COMPARISON OF ACCURACY IN RANKING ALTERNATIVES PERFORMING GENERALIZED FUZZY AVERAGE FUNCTIONS
}

\author{
Natalja KOSAREVA ${ }^{\mathrm{a}}$, Aleksandras KRYLOVAS \\ ${ }^{a}$ Vilnius Gediminas Technical University, Sauletekio al. 11, LT-10223 Vilnius, Lithuania \\ ${ }^{\mathrm{b}}$ Faculty of Economics and Finance Management, Mykolas Romeris University, \\ Ateities g. 20, LT-08303 Vilnius, Lithuania
}

Received 10 May 2012; accepted 22 September 2012

\begin{abstract}
The paper defines the notions of point, interval and triangular intuitionistic fuzzy numbers expressing the degree of membership and non-membership in the fuzzy set. The generalized fuzzy weighted average function is introduced according to operation rules on intuitionistic fuzzy numbers. In special cases, the generalized weighted average coincides with an arithmetic average or a geometric average. The generalized fuzzy weighted average function could be applied for solving problems in multiple criteria decision making. Research on the stability of the generalized weighted averaging operator of ranking alternatives was performed applying the Monte Carlo method. The aim of the conducted research is to establish the types of intuitionistic fuzzy numbers and the exponent values of the generalized weighted averaging operator having the least error probabilities considering alternatives ranking. Computations were performed involving 3,4 and 5 experts. In the case of 5 experts, initial decision matrices having high, middle and low separability alternatives were examined. Decision matrices created by the experts were modelled generating random intuitionistic fuzzy numbers according to uniform and normal distribution. The example of applying such methodology was shown to solve a real problem of ranking possible redevelopment alternatives for derelict rural buildings.
\end{abstract}

Keywords: intuitionistic fuzzy number, generalized weighted averaging operator, multiple criteria decision making, Monte Carlo method.

Reference to this paper should be made as follows: Kosareva, N.; Krylovas, A. 2013. Comparison of accuracy in ranking alternatives performing generalized fuzzy average functions, Technological and Economic Development of Economy 19(1): 162-187.

JEL Classification: D81, C44, C63, O18.

Corresponding address:

N. Kosareva E-mail: Natalja.Kosareva@vgtu.lt 


\section{Introduction}

The current paper mainly deals with Multiple Criteria Decision Making (MCDM) in a fuzzy environment. MCDM is a branch of Operations Research (OR) aimed at making the best decision according to several criteria. The quality of the reached decision relates to maximizing profit or utility and minimizing loss or cost.

In MCDM, we have a finite set of alternatives or projects to select the best one according to their adequacy to a finite set of attributes. Each attribute has its importance expressed by weight. In the decision matrix, project adequacy to attributes is expressed by crisp numbers. There are many methods for determining the order of alternatives in terms of a set of attributes or criteria. Several well-known methods for dealing with multiple criteria decision making problems are, for example, Multiplicative Exponential Weighting (MEW), Simple Additive Weighting (SAW), Technique for Ordering Preference by Similarity to Ideal Solution (TOPSIS), a method of multiple criteria Complex Proportional Assessment of Projects (COPRAS), Additive Ratio Assessment method (ARAS), Multi-objective Optimization by Ratio Analysis method (MOORA), ELECTRE, etc. MCDM methods were overviewed and classified according to available information and their application for solving economical decision problems (Hwang, Yoon 1981; Figueira et al. 2005; Zavadskas, Turskis 2011).

Under real conditions, vague or imprecise information creates difficulties in assigning a crisp value of a subjective judgment - an element of the decision matrix. Such information is better determined using fuzzy numbers. Sometimes the subjective judgment is defined as a linguistic variable, i.e. the variable the values of which are expressed in linguistic terms (Zimmermann 1985). Fuzzy numbers appropriately express linguistic variables. A fuzzy multiple criteria decision making (FMCDM) theory is an appropriate solution in such circumstances. Fuzzy numbers in the fuzzy multiple criteria decision making approach (in our case, intuitionistic fuzzy numbers) are the elements of the decision matrix (Deng 2009). Other approach is to deal with attribute weights as intuitionistic fuzzy numbers (Liu 2009). The ordered weighted averaging (OWA) operator was introduced by Yager (1988). Zhao et al. (2010) developed some new generalized aggregation operators such as a generalized intuitionistic fuzzy ordered weighted averaging operator. Merigo and Wei (2011) investigated an uncertain probabilistic ordered weighted averaging (UPOWA) operator. Han and Liu (2011) were solving unknown attribute weights and hybrid multiple attribute decision-making problems under risk. Zavadskas and Turskis (2011) presented a comprehensive overview of multiple criteria decision making methods in an uncertain environment along with their classification and applications.

A methodology of fuzzy sets introduced by Zadeh (1965) has been extended and enriched and nowadays is being widely applied in many fields of scientific research such as knowledge management systems, project management, manufacturing and organizational strategy, evaluating investment direction and magnitude, etc. MCDM is one of the branches where the fuzzy set theory has been found a wide application area.

Atanassov (1986) formulated a concept of an intuitionistic fuzzy set (IFS) as the generalization of the notion of the fuzzy set. He stated that IFSs had essentially higher describing possibilities than fuzzy sets. The IFS has gained wide recognition as a useful tool for modelling 
uncertain phenomena. Atanassov and Gargov (1989) extended the IFS to the interval valued intuitionistic fuzzy set (IVIFS) and defined operation rules for intuitionistic fuzzy numbers (IFNs). Xu (2007a) proposed some methods for aggregating interval valued intuitionistic fuzzy information that can be applied for reaching a solution to decision making problems. Zhang and Liu (2010) used the triangular intuitionistic fuzzy number and weighted arithmetic and geometric averaging operators for decision making. Wei et al. (2012) investigated multiple attribute group decision making problems where both attribute weights and expert weights take the form of real numbers and attribute values take the form of interval intuitionistic trapezoidal fuzzy numbers.

In fuzzy MCDM (FMCDM), the values of fuzzy information aggregation operators are the set of intuitionistic fuzzy numbers (one for each alternative). Thus, we obtain the problem of ranking fuzzy alternatives. Due to the fact that fuzzy numbers are not linearly ordered, ranking them is one of the fundamental problems of fuzzy decision making. This problem is still important in the case of intuitionistic fuzzy numbers. The widely used approach to compare fuzzy numbers is their defuzzification into crisp numbers. Then, ranking based on these crisp numbers is done.

The purpose of our research is to compare various methods of aggregating fuzzy information in multiple criteria decision making. For this purpose, the Monte Carlo simulation method was applied. Zanakis et al. (1998) employed this technique for comparing various MCDM methods. The tasks we intended to accomplish included:

- comparing alternative ranking results obtained with the help of the weighted arithmetic averaging operator and weighted geometric averaging operator in cases of various types of intuitionistic fuzzy numbers (point intuitionistic fuzzy numbers, interval valued intuitionistic fuzzy numbers and triangular intuitionistic fuzzy numbers);

- comparing the stability of the generalized weighted averaging operator of ranking alternatives obtained from different types of intuitionistic fuzzy numbers, initial decision matrices and exponent values of the generalized weighted averaging operator.

\section{Intuitionistic fuzzy numbers}

The notion of an intuitionistic fuzzy set was introduced by (Atanassov 1986).

Definition 1.1. Let $X$ be a finite non empty set. An intuitionistic fuzzy set on $X$ is an expression given by $A=\left\{\left\langle x, \mu_{A}(x), v_{A}(x)>\right| x \in X\right\}$ where $\mu_{A}(x): X \rightarrow[0 ; 1], v_{A}(x): X \rightarrow[0 ; 1]$ and $0 \leq \mu_{A}(x)+v_{A}(x) \leq 1$ for all $x \in X . \mu_{A}(x)$ is the membership degree and $v_{A}(x)$ is the non-membership degree of element $x \in A . \pi_{A}(x)=1-\mu_{A}(x)-v_{A}(x)$ is the degree of uncertainty (indeterminacy) associated with the membership of element $x$ in $A$.

In the special case of $\pi_{A}(x)=1-\mu_{A}(x)+v_{A}(x)=0, \forall x \in X$ we have fuzzy set $A$ instead of the IFS. We will restrict our consideration to intuitionistic fuzzy numbers, henceforth our set $X$ would be real line $X=R$. Burillo et al. (1994) defined an intuitionistic fuzzy number as follows. 
Definition 1.2. The intuitionistic fuzzy subset $\tilde{A}=\left\{<x, \mu_{\tilde{A}}(x), v_{\tilde{A}}(x)>\mid x \in R\right\}$ of the real line is called the intuitionistic fuzzy number if:

i) $\tilde{A}$ is normal, i.e. $x_{0} \in R$ that $\mu_{\tilde{A}}\left(x_{0}\right)=1\left(\right.$ so $v_{\tilde{A}}\left(x_{0}\right)=0$ ) exist;

ii) membership function $\mu_{\tilde{A}}(x)$ is fuzzy convex:

$$
\mu_{\tilde{A}}\left(\lambda x_{1}+(1-\lambda) x_{2}\right) \geq \min \left(\mu_{\tilde{A}}\left(x_{1}\right), \mu_{\tilde{A}}\left(x_{2}\right)\right) \forall x_{1}, x_{2} \in R, \lambda \in[0 ; 1]
$$

iii) non membership function $v_{\tilde{A}}(x)$ is fuzzy concave:

$$
v_{\tilde{A}}\left(\lambda x_{1}+(1-\lambda) x_{2}\right) \leq \max \left(v_{\tilde{A}}\left(x_{1}\right), v_{\tilde{A}}\left(x_{2}\right)\right) \forall x_{1}, x_{2} \in R, \lambda \in[0 ; 1] .
$$

Fig. 1 shows two intuitionistic fuzzy numbers, the degree of the uncertainty of the first number (on the left figure) is $\pi_{A}(x)=1-\mu_{A}(x)-v_{A}(x) \equiv 0$; thus, it is a special case of the fuzzy number. The figure on the right depicts an intuitionistic fuzzy number with $0 \leq \pi_{A}(x)<1, \forall x \in A$.

For simplicity, the IFN is denoted by $(a, b)$ where $a, b \in R, a+b \leq 1$. Let $\tilde{A}_{1}=\left(a_{1}, b_{1}\right)$, $\tilde{A}_{2}=\left(a_{2}, b_{2}\right)$ be two intuitionistic fuzzy numbers. The operation rules of IFSs are defined as follows (Atanassov, Gargov 1989):

$$
\begin{gathered}
\tilde{A}_{1}+\tilde{A}_{2}=\left(a_{1}+a_{2}-a_{1} a_{2}, b_{1} b_{2}\right) ; \\
\tilde{A}_{1} \tilde{A}_{2}=\left(a_{1} a_{2}, b_{1}+b_{2}-b_{1} b_{2}\right) ; \\
\lambda \tilde{A}_{1}=\left(1-\left(1-a_{1}\right)^{\lambda}, b_{1}^{\lambda}\right), \lambda>0 ; \\
\tilde{A}_{1}^{\lambda}=\left(a_{1}^{\lambda}, 1-\left(1-b_{1}\right)^{\lambda}\right), \lambda>0 .
\end{gathered}
$$
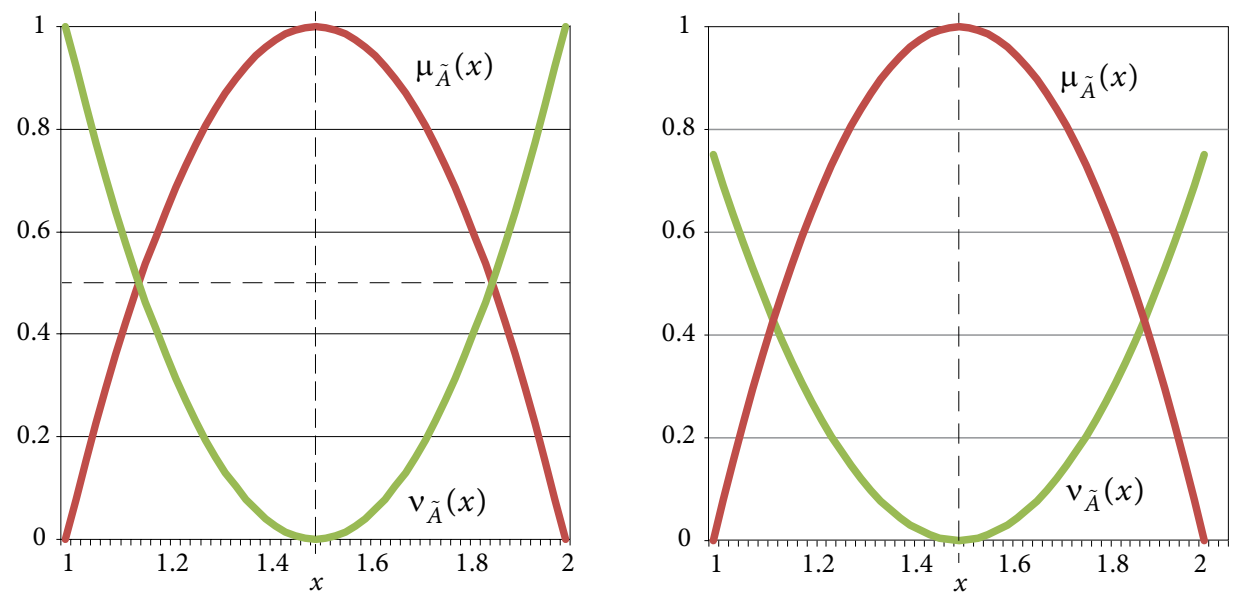

Fig. 1. Intuitionistic fuzzy number $\tilde{A}$ with its membership function $\mu_{\tilde{A}}(x)$ and non membership function $v_{\tilde{A}}(x)$ 
Atanassov and Gargov (1989) introduced the notion of an interval valued intuitionistic fuzzy number. Bustince and Burillo (1995) presented a theorem that allows constructing interval valued intuitionistic fuzzy sets from intuitionistic fuzzy sets and to recover intuitionistic fuzzy sets used for constructing the interval valued intuitionistic fuzzy set from different operators.

Definition 1.3. Let $X$ be a finite non empty set. The interval valued intuitionistic fuzzy set on $X$ is an expression given by $A=\left\{\left\langle x, M_{A}(x), N_{A}(x)\right\rangle \mid x \in X\right\}$, where $M_{A}(x)=\left[M_{A L} ; M_{A U}\right] \subset[0 ; 1], N_{A}(x)=\left[N_{A L} ; N_{A U}\right] \subset[0 ; 1]$ and $0 \leq M_{A U}(x)+N_{A U}(x) \leq 1$ for all $x \in X$. Intervals $M_{A}(x)$ and $N_{A}(x)$ denote the degree of membership and the degree of non-membership of element $x \in A$ respectively.

Zhang and Liu (2010) used triangular fuzzy numbers to express membership degree $\mu_{A}(x)$ and non-membership degree $v_{A}(x)$ of element $x \in A$. The triangular intuitionistic fuzzy set is the generalization of the notion of the intuitionistic fuzzy set. The general form of the triangular intuitionistic fuzzy number is $\left(\left[a^{L}, a^{M}, a^{U}\right],\left[b^{L}, b^{M}, b^{U}\right]\right), 0 \leq a^{U}+b^{U} \leq 1$, where $\left(a^{L}, a^{M}, a^{U}\right)$ and $\left(b^{L}, b^{M}, b^{U}\right)$ are triangular fuzzy numbers. In this case, $a^{L}, b^{L}$ are lower extreme values, $a^{M}, b^{M}$ - mean values and $a^{U}, b^{U}$ - upper extreme values of the membership degree and non-membership degree of element $x \in A$ respectively.

Let $\tilde{A}_{1}=\left(\left[a_{1}^{L}, a_{1}^{M}, a_{1}^{U}\right],\left[b_{1}^{L}, b_{1}^{M}, b_{1}^{U}\right]\right), \tilde{A}_{2}=\left(\left[a_{2}^{L}, a_{2}^{M}, a_{2}^{U}\right],\left[b_{2}^{L}, b_{2}^{M}, b_{2}^{U}\right]\right)$, be two triangular intuitionistic fuzzy numbers operation rules on which are defined as follows:

$$
\begin{gathered}
\tilde{A}_{1}+\tilde{A}_{2}=\left(\left[a_{1}^{L}+a_{2}^{L}-a_{1}^{L} a_{2}^{L}, a_{1}^{M}+a_{2}^{M}-a_{1}^{M} a_{2}^{M}, a_{1}^{U}+a_{2}^{U}-a_{1}^{U} a_{2}^{U}\right],\left[b_{1}^{L} b_{2}^{L}, b_{1}^{M} b_{2}^{M}, b_{1}^{U} b_{2}^{U}\right]\right) ; \\
\tilde{A}_{1} \cdot \tilde{A}_{2}=\left(\left[a_{1}^{L} a_{2}^{L}, a_{1}^{M} a_{2}^{M}, a_{1}^{U} a_{2}^{U}\right],\left[b_{1}^{L}+b_{2}^{L}-b_{1}^{L} b_{2}^{L}, b_{1}^{M}+b_{2}^{M}-b_{1}^{M} b_{2}^{M}, b_{1}^{U}+b_{2}^{U}-b_{1}^{U} b_{2}^{U}\right]\right) ; \\
\lambda \tilde{A}_{1}=\left(\left[1-\left(1-a_{1}^{L}\right)^{\lambda}, 1-\left(1-a_{1}^{M}\right)^{\lambda}, 1-\left(1-a_{1}^{U}\right)^{\lambda}\right],\left[\left(b_{1}^{L}\right)^{\lambda},\left(b_{1}^{M}\right)^{\lambda},\left(b_{1}^{U}\right)^{\lambda}\right]\right), \lambda \geq 0 ; \\
\tilde{A}_{1}^{\lambda}=\left(\left[\left(a_{1}^{L}\right)^{\lambda},\left(a_{1}^{M}\right)^{\lambda},\left(a_{1}^{U}\right)^{\lambda}\right],\left[1-\left(1-b_{1}^{L}\right)^{\lambda}, 1-\left(1-b_{1}^{M}\right)^{\lambda}, 1-\left(1-b_{1}^{U}\right)^{\lambda}\right]\right), \lambda \geq 0 ;
\end{gathered}
$$

$\mathrm{Xu}(2007 \mathrm{a})$ defined aggregation operators of IFNs as follows.

Definition 1.4. Suppose $\tilde{A}_{i}(i=1,2, \ldots, n)$ is a set of triangular intuitionistic fuzzy numbers and $f_{\omega}: \Omega^{n} \rightarrow \Omega, \Omega$ is a set of all triangular intuitionistic fuzzy numbers. If

$$
f_{\omega}\left(\tilde{A}_{1}, \tilde{A}_{2}, \ldots, \tilde{A}_{n}\right)=\sum_{i=1}^{n} \omega_{i} \tilde{A}_{i},
$$

where $\omega=\left(\omega_{1}, \omega_{1}, \ldots, \omega_{n}\right)^{T}, \omega_{i} \in[0 ; 1], \sum_{i=1}^{n} \omega_{i}=1$ is the weight vector of $\tilde{A}_{i}(i=1,2, \ldots, n)$. Then, function $f_{\omega}$ is called the weighted arithmetic averaging operator of triangular intuitionistic fuzzy numbers.

Definition 1.5. Under conditions described in Definition 1.4., function $g_{\omega}: \Omega^{n} \rightarrow \Omega$ can be defined as follows:

$$
g_{\omega}\left(\tilde{A}_{1}, \tilde{A}_{2}, \ldots, \tilde{A}_{n}\right)=\prod_{i=1}^{n}\left(\tilde{A}_{i}\right)^{\omega_{i}}
$$


where $\omega=\left(\omega_{1}, \omega_{1}, \ldots, \omega_{n}\right)^{T}, \omega_{i} \in[0 ; 1], \sum_{i=1}^{n} \omega_{i}=1$ is the weight vector of $\tilde{A}_{i}(i=1,2, \ldots, n)$ and is called the weighted geometric averaging operator of triangular intuitionistic fuzzy numbers.

Two formulas for aggregation operations in a set of triangular intuitionistic fuzzy numbers have been established (Zhang, Liu 2010). The proof of these formulas follows immediately from formulas (1)-(2) and operation rules on triangular intuitionistic fuzzy numbers. Suppose $\tilde{A}_{i}=\left(\left[a_{i}^{L}, a_{i}^{M}, a_{i}^{U}\right],\left[b_{i}^{L}, b_{i}^{M}, b_{i}^{U}\right]\right),(i=1,2, \ldots, n)$ is a set of triangular intuitionistic fuzzy numbers. Then, the result of the arithmetic averaging operator is a triangular intuitionistic fuzzy number and

$$
\begin{aligned}
& f_{\omega}\left(\tilde{A}_{1}, \tilde{A}_{2}, \ldots, \tilde{A}_{n}\right)=\sum_{i=1}^{n} \omega_{i} \tilde{A}_{i}= \\
& \left(\left[1-\prod_{i=1}^{n}\left(1-a_{i}^{L}\right)^{\omega_{i}}, 1-\prod_{i=1}^{n}\left(1-a_{i}^{M}\right)^{\omega_{i}}, 1-\prod_{i=1}^{n}\left(1-a_{i}^{U}\right)^{\omega_{i}}\right],\left[\prod_{i=1}^{n}\left(b_{i}^{L}\right)^{\omega_{i}}, \prod_{i=1}^{n}\left(b_{i}^{M}\right)^{\omega_{i}}, \prod_{i=1}^{n}\left(b_{i}^{U}\right)^{\omega_{i}}\right]\right) .
\end{aligned}
$$

Suppose $\tilde{A}_{i}=\left(\left[a_{i}^{L}, a_{i}^{M}, a_{i}^{U}\right],\left[b_{i}^{L}, b_{i}^{M}, b_{i}^{U}\right]\right),(i=1,2, \ldots, n)$ is a set of triangular intuitionistic fuzzy numbers. Then, the result of the geometric averaging operator is a triangular intuitionistic fuzzy number and

$$
\begin{aligned}
& g_{\omega}\left(\tilde{A}_{1}, \tilde{A}_{2}, \ldots, \tilde{A}_{n}\right)=\prod_{i=1}^{n}\left(\tilde{A}_{i}\right)^{\omega_{i}}= \\
& \left(\left[\prod_{i=1}^{n}\left(a_{i}^{L}\right)^{\omega_{i}}, \prod_{i=1}^{n}\left(a_{i}^{M}\right)^{\omega_{i}}, \prod_{i=1}^{n}\left(a_{i}^{U}\right)^{\omega_{i}}\right],\left[1-\prod_{i=1}^{n}\left(1-b_{i}^{L}\right)^{\omega_{i}}, 1-\prod_{i=1}^{n}\left(1-b_{i}^{M}\right)^{\omega_{i}}, 1-\prod_{i=1}^{n}\left(1-b_{i}^{U}\right)^{\omega_{i}}\right]\right) .(4)
\end{aligned}
$$

\section{Ranking intuitionistic fuzzy numbers}

A number of researchers have analyzed the problem of comparing fuzzy numbers. Intuitionistic fuzzy weighted averaging operators are used for aggregating individual opinions of decision makers to have a combined opinion. As a result, intuitionistic fuzzy numbers (one for each alternative) are obtained. One of the most frequently used comparison methods is the defuzzification of fuzzy numbers, i.e. transforming them to crisp numbers can be easily compared. Chen and Tan (1994) provided a score function to defuzzificate intuitionistic fuzzy numbers.

Definition 2.1. Let $\tilde{A}=(a, b)$ be an intuitionistic fuzzy number. The score function $S$ of intuitionistic fuzzy number $\tilde{A}$ is represented as follows:

$$
S_{\tilde{A}}=a-b, S_{\tilde{A}} \in[-1 ; 1] .
$$

The larger is the score of $S_{\tilde{A}}$, the greater is intuitionistic fuzzy number $\tilde{A}$.

Hong and Choi (2000) proposed improved comparison technique based on the score function and accuracy function.

Definition 2.2. Let $\tilde{A}=(a, b)$ be an intuitionistic fuzzy number. The accuracy function $H$ of intuitionistic fuzzy number $\tilde{A}$ is represented as follows: $H_{\tilde{A}}=a+b, H_{\tilde{A}} \in[0 ; 1]$.

If the score function values of two IFNs coincide, then, the larger is the accuracy of $H_{\tilde{A}}$, the greater is intuitionistic fuzzy number $\tilde{A}$.

$\mathrm{Xu}$ (2007b) generalized these definitions for interval valued intuitionistic fuzzy numbers. 
Definition 2.3. Let $\tilde{A}=\left(\left[a^{L}, a^{U}\right],\left[b^{L}, b^{U}\right]\right)$ be an interval valued intuitionistic fuzzy number. The score function $S_{\tilde{A}}$ of $\tilde{A}$ is represented as follows:

$$
S_{\tilde{A}}=\left(a^{L}-b^{L}+a^{U}-b^{U}\right) / 2, S_{\tilde{A}} \in[-1 ; 1] .
$$

Definition 2.4. Let $\tilde{A}=\left(\left[a^{L}, a^{U}\right],\left[b^{L}, b^{U}\right]\right)$ be an interval valued intuitionistic fuzzy number. The accuracy function $H_{\tilde{A}}$ of $\tilde{A}$ is represented as follows: $H_{\tilde{A}}=\left(a^{L}+b^{L}+a^{U}+b^{U}\right) / 2, H_{\tilde{A}} \in[0 ; 1]$.

According to Zhang and Liu (2010), the score function and accuracy function of the triangular intuitionistic fuzzy number are defined in a similar way.

Definition 2.5. Suppose $\tilde{A}=\left(\left[a^{L}, a^{M}, a^{U}\right],\left[b^{L}, b^{M}, b^{U}\right]\right)$ is a triangular intuitionistic fuzzy number. Then, $S_{\tilde{A}} \in[-1 ; 1]$ is called the score function of $\tilde{A}$ :

$$
S_{\tilde{A}}=\left(a^{L}-b^{L}+a^{M}-b^{M}+a^{U}-b^{U}\right) / 3 .
$$

Definition 2.6. Suppose $\tilde{A}=\left(\left[a^{L}, a^{M}, a^{U}\right],\left[b^{L}, b^{M}, b^{U}\right]\right)$ is a triangular intuitionistic fuzzy number. Then, $H_{\tilde{A}} \in[0 ; 1]$ is called the accuracy function of $\tilde{A}$ :

$$
H_{\tilde{A}}=\left(a^{L}+b^{L}+a^{M}+b^{M}+a^{U}+b^{U}\right) / 3 .
$$

Based on score function $S_{\tilde{A}}$ and accuracy function $H_{\tilde{A}} \mathrm{Xu}(2007 \mathrm{~b})$ proposed an order relation between two intuitionistic fuzzy values defined as follows.

Proposition 2.1. Let $\tilde{A}_{1}=\left(a_{1}, b_{1}\right)$ and $\tilde{A}_{2}=\left(a_{2}, b_{2}\right)$ be two intuitionistic fuzzy numbers, $S_{\tilde{A}_{1}}, S_{\tilde{A}_{2}}$ - the scores of $\tilde{A}_{1}$ and $\tilde{A}_{2}$ and $H_{\tilde{A}_{1}}, H_{\tilde{A}_{2}}$ - the accuracy degrees of $\tilde{A}_{1}$ and $\tilde{A}_{2}$ respectively. Then,

1. if $S_{\tilde{A}_{1}}<S_{\tilde{A}_{2}}$, then $\tilde{A}_{1}$ is smaller than $\tilde{A}_{2}$ denoted by $\tilde{A}_{1} \prec \tilde{A}_{2}$;

2. if $S_{\tilde{A}_{1}}=S_{\tilde{A}_{2}}$, then

2.1. if $H_{\tilde{A}_{1}}<H_{\tilde{A}_{2}}$, then $\tilde{A}_{1}$ is smaller than $\tilde{A}_{2}$ denoted by $\tilde{A}_{1} \prec \tilde{A}_{2}$;

2.2. if $H_{\tilde{A}_{1}}=H_{\tilde{A}_{2}}$, then $\tilde{A}_{1}$ and $\tilde{A}_{2}$ represent the same information denoted by $\tilde{A}_{1}=\tilde{A}_{2}$.

As an example, compare two triangular IFNs:

$\tilde{A}_{1}=([0.4,0.5,0.65],[0.2,0.25,0.3])$ and $\tilde{A}_{2}=([0.45,0.5,0.55],[0.15,0.25,0.3])$.

Score functions of these IFNs coincide with $S_{\tilde{A}_{1}}=S_{\tilde{A}_{2}}=\frac{0.8}{3} \approx 0.2667$; thus, accuracy functions $H_{\tilde{A}_{1}}=\frac{2.3}{3} \approx 0.7667, H_{\tilde{A}_{2}}=\frac{2.2}{3} \approx 0.7333$ must be compared. According to proposition 2.1., intuitionistic fuzzy numbers $\tilde{A}_{1}$ and $\tilde{A}_{2}$ can be ranked as follows: $\tilde{A}_{1} \succ \tilde{A}_{2}$.

\section{Multiple criteria decision making by aggregated fuzzy functions}

The fuzzy multiple criteria decision making approach implies that $S=\left(s_{1}, s_{2}, \ldots, s_{m}\right)$ is a finite set of alternatives from which decision makers have to select the best one, evaluate or rank altern- 
atives according to the weights of the finite set of attributes $R=\left(r_{1}, r_{2}, \ldots, r_{n}\right)$. The weight vector of attributes is $\omega=\left(\omega_{1}, \omega_{1}, \ldots, \omega_{n}\right)^{T}, \omega_{i} \in[0 ; 1], \sum_{i=1}^{n} \omega_{i}=1$. The elements of the decision matrix are triangular intuitionistic fuzzy numbers $D=\left(D_{i j}\right)_{m \times n}, D_{i j}=\left(\left[a_{i j}^{L}, a_{i j}^{M}, a_{i j}^{U}\right],\left[b_{i j}^{L}, b_{i j}^{M}, b_{i j}^{U}\right]\right)$ where $\mu_{i}\left(r_{j}\right)=\left(\left[a_{i j}^{L}, a_{i j}^{M}, a_{i j}^{U}\right]\right)$ denotes the satisfaction degree of project $s_{i}$ to attribute $r_{j}$ and $v_{i}\left(r_{j}\right)=\left(\left[b_{i j}^{L}, b_{i j}^{M}, b_{i j}^{U}\right]\right)$ denotes the non-satisfaction degree of project $s_{i}$ to attribute $r_{j}$. The multiple criteria decision making method based on triangular intuitionistic fuzzy numbers, according to Zhang and Liu (2010), could be accomplished following the below introduced steps.

1. The creation of a combined decision matrix. The elements of such matrix reflect the opinions of different evaluators (experts) and consist of information collected from all evaluators. Experts evaluate every element of the decision matrix with reference to an intuitionistic fuzzy number. The element of the combined decision matrix is created as follows: $a_{i j}^{L}, a_{i j}^{M}, a_{i j}^{U}$ are the minimum, average and maximum values of evaluators denoting the satisfaction degree of project $s_{i}$ to attribute $r_{j}$ while $b_{i j}^{L}, b_{i j}^{M}, b_{i j}^{U}$ are the minimum, average and maximum values of evaluators denoting the non-satisfaction degree of project $s_{i}$ to attribute $r_{j}$.

2. Aggregating project information. For every row of the decision matrix containing information corresponding to project $i$, the weighted arithmetic averaging operator $I_{i}^{f}=f_{\omega}\left(D_{i 1}, D_{i 2}, \ldots, D_{i n}\right), i=1,2, \ldots, m$ or the weighted geometric averaging operator $I_{i}^{g}=g_{\omega}\left(D_{i 1}, D_{i 2}, \ldots, D_{i n}\right), i=1,2, \ldots, m$ according to formulas (3) and (4) is calculated. Thus, all information associated with project $i$ is aggregated.

3. Calculating the values of score function $S\left(I_{i}^{f}\right), S\left(I_{i}^{g}\right)$ and accuracy function $H\left(I_{i}^{f}\right), H\left(I_{i}^{g}\right)$. According to formulas (7) and (8), the values of the score function and, in case it is necessary, the values of accuracy function for $I_{i}^{f}$ and $I_{i}^{g}$ are calculated. It is a defuzzification procedure converting each aggregated triangular fuzzy number into a crisp value for ranking and further analysis.

4. Comparing projects. On the grounds of Proposition 2.1., the best project from $m$ project set is selected.

We can similarly operate with (point) intuitionistic fuzzy numbers and interval valued intuitionistic fuzzy numbers.

\section{Aggregated fuzzy functions based on the generalized averaging operator}

We want to extend the notions of aggregation operations on a set of triangular intuitionistic fuzzy numbers.

Definition 4.1. Suppose $\tilde{A}_{i}(i=1,2, \ldots, n)$ is a set of triangular intuitionistic fuzzy numbers, $p>0, p \in R$ and $f_{\omega}^{p}: \Omega^{n} \rightarrow \Omega, \Omega$ - a set of all triangular intuitionistic fuzzy numbers. If

$$
f_{\omega}^{p}\left(\tilde{A}_{1}, \tilde{A}_{2}, \ldots, \tilde{A}_{n}\right)=\left(\sum_{i=1}^{n} \omega_{i} \tilde{A}_{i}^{p}\right)^{1 / p}
$$


where $\omega=\left(\omega_{1}, \omega_{1}, \ldots, \omega_{n}\right)^{T}, \omega_{i} \in[0 ; 1], \sum_{i=1}^{n} \omega_{i}=1$ is the weight vector of $\tilde{A}_{i}(i=1,2, \ldots, n)$, function $f_{\omega}^{p}$ is called the generalized weighted averaging operator with the exponent $p$ of triangular intuitionistic fuzzy numbers.

Remark 1. If $p=1$, then, the generalized weighted averaging operator coincides with the arithmetic averaging operator described by (3).

Remark 2. The limit of the generalized weighted averaging operator, when $p \rightarrow 0$, coincides with the geometric averaging operator described by (4):

$$
\lim _{p \rightarrow 0} f_{\omega}^{p}\left(\tilde{A}_{1}, \tilde{A}_{2}, \ldots, \tilde{A}_{n}\right)=g_{\omega}\left(\tilde{A}_{1}, \tilde{A}_{2}, \ldots, \tilde{A}_{n}\right)=\prod_{i=1}^{n}\left(\tilde{A}_{i}\right)^{\omega_{i}}
$$

Suppose $\tilde{A}_{i}=\left(\left[a_{i}^{L}, a_{i}^{M}, a_{i}^{U}\right],\left[b_{i}^{L}, b_{i}^{M}, b_{i}^{U}\right]\right),(i=1,2, \ldots, n)$ is a set of triangular intuitionistic fuzzy numbers. Then, according to formula (9) and operation rules for triangular intuitionistic fuzzy numbers, the result of the generalized weighted averaging operator with exponent $p$ is a triangular intuitionistic fuzzy number. A formula for calculating the generalized weighted averaging operator in the set of triangular IFNs proposed by Zhao et al. (2010) is as follows:

$$
\begin{aligned}
& f_{\omega}^{p}\left(\tilde{A}_{1}, \tilde{A}_{2}, \ldots, \tilde{A}_{n}\right)=\left(\left[\left(1-\prod_{i=1}^{n}\left(1-\left(a_{i}^{L}\right)^{p}\right)^{\omega_{i}}\right)^{1 / p},\left(1-\prod_{i=1}^{n}\left(1-\left(a_{i}^{M}\right)^{p}\right)^{\omega_{i}}\right)^{1 / p},\left(1-\prod_{i=1}^{n}\left(1-\left(a_{i}^{U}\right)^{p}\right)^{\omega_{i}}\right)^{1 / p}\right] ;\right. \\
& \left.\left[1-\left(1-\prod_{i=1}^{n}\left(1-\left(1-b_{i}^{L}\right)^{p}\right)^{\omega_{i}}\right)^{1 / p}, 1-\left(1-\prod_{i=1}^{n}\left(1-\left(1-b_{i}^{M}\right)^{p}\right)^{\omega_{i}}\right)^{1 / p}, 1-\left(1-\prod_{i=1}^{n}\left(1-\left(1-b_{i}^{U}\right)^{p}\right)^{\omega_{i}}\right)^{1 / p}\right]\right) .
\end{aligned}
$$

\section{Monte Carlo research on the stability of the generalized weighted averaging operator considering ranking alternatives}

Initially design our research. Suppose we have 5 experts and 5 alternative projects that must be ranked according to 5 criteria. There are 3 versions of initial decision matrices the elements $D_{i j}$ of which reflect the satisfaction degree of project $s_{i}, i=1,2, \ldots .5$ to attribute $r_{j}, j=1,2, \ldots 5$ and are represented by crisp numbers. Initial decision matrices reflect an objective (true) judgment of projects. The weights of criteria are considered as equal, i.e. their importance is equal to $\omega=(0.2,0.2,0.2,0.2,0.2)^{T}$. Initial decision matrices are given in Table 1 . The first matrix shows high, the second - medium and the third - low separability of alternatives:

Nevertheless, we can easily check that for all 3 decision matrices and equal weights of criteria, the ranking results of alternatives, according to all our surveyed methods, would be the same: $s_{1} \succ s_{2} \succ s_{3} \succ s_{4} \succ s_{5}$.

The elements of the Monte Carlo experiment involving 5 expert decision matrixes are intuitionistic fuzzy numbers randomly generated from the values of the initial matrixes given in Table 1 by uniform or normal distribution with different variance values. 
Table 1 . The initial matrices for high, medium and low separability alternatives

\begin{tabular}{cccccccccccccccc}
\hline & \multicolumn{1}{c}{ High separability } & \multicolumn{1}{c}{ Medium separability } & \multicolumn{7}{c}{ Low separability } \\
\hline & $r_{1}$ & $r_{2}$ & $r_{3}$ & $r_{4}$ & $r_{5}$ & $r_{1}$ & $r_{2}$ & $r_{3}$ & $r_{4}$ & $r_{5}$ & $r_{1}$ & $r_{2}$ & $r_{3}$ & $r_{4}$ & $r_{5}$ \\
\hline$s_{1}$ & 0.8 & 0.8 & 0.8 & 0.8 & 0.8 & 0.65 & 0.65 & 0.65 & 0.65 & 0.65 & 0.65 & 0.65 & 0.65 & 0.55 & 0.55 \\
\hline$s_{2}$ & 0.65 & 0.65 & 0.65 & 0.65 & 0.65 & 0.55 & 0.55 & 0.55 & 0.55 & 0.55 & 0.55 & 0.55 & 0.55 & 0.55 & 0.65 \\
\hline$s_{3}$ & 0.5 & 0.5 & 0.5 & 0.5 & 0.5 & 0.45 & 0.45 & 0.45 & 0.45 & 0.45 & 0.45 & 0.45 & 0.45 & 0.35 & 0.55 \\
\hline$s_{4}$ & 0.35 & 0.35 & 0.35 & 0.35 & 0.35 & 0.35 & 0.35 & 0.35 & 0.35 & 0.35 & 0.35 & 0.35 & 0.35 & 0.25 & 0.55 \\
\hline$s_{5}$ & 0.2 & 0.2 & 0.2 & 0.2 & 0.2 & 0.25 & 0.25 & 0.25 & 0.25 & 0.25 & 0.25 & 0.25 & 0.25 & 0.45 & 0.55 \\
\hline
\end{tabular}

In the case of fuzzy numbers, the standard procedures of generating a random number could be applied. As FNs have 2 components - the degree of membership $\mu_{a}$ and the degree of non-membership $v_{a}$ related by equation $\mu_{a}+v_{a}=1$ - it is enough to generate only one component, for example, $\mu_{a}$. In the case of IFNs, there are two degrees of freedom - the degree of membership and the degree of uncertainty. Therefore, for IFNs, the procedure of generation must be applied twice. The method of an inverse cumulative distribution function, as described by Gentle (2003), has been used. Supposedly, the judgment of each expert is a random number that does not differ significantly from an objective judgment. At the stage of planning our experiment, the idea of evaluating the degrees of membership and non-membership independently have been used (Dubois et al. 2005). The fuzzy number of expert evaluation $\left(\mu_{a}, v_{a}\right)$ is generated by normal distribution from crisp number $a$ in the following way. For the fixed $\sigma$ value, random number $X_{1}$ from normal distribution with average $E X_{1}=a$ and standard deviation $\sqrt{D X_{1}}=\sigma$ is generated. $\mu_{a}$ is the realization of random variable $X_{1}$. Then, the degree of uncertainty $\pi_{a}$ is formed, which is the realization of random variable $X_{2}$ having normal distribution with $E X_{2}=0.1, \sqrt{D X_{2}}=0.05$. Next, $v_{a}=1-\mu_{a}-\pi_{a}$ is calculated.

Generation by uniform distribution was performed in a similar way. $X_{1}$ as a uniform random variable in the interval $[a-\sigma, a+\sigma]$ and $X_{2}$ as a uniform random variable in the interval $[0.05,0.15]$ have been generated.

The realization of the generated decision matrix of high separability alternatives in the case of normal distribution when $\sigma=0.2$ is presented in Table 2 .

Table 2 . The realization of the decision matrix of high separability alternatives applying normal distribution when $\sigma=0.2$

\begin{tabular}{cccccc}
\hline & $r_{1}$ & $r_{2}$ & $r_{3}$ & $r_{4}$ & $r_{5}$ \\
\hline$s_{1}$ & $(0.824,0.066)$ & $(0.868,0.0)$ & $(0.826,0.027)$ & $(0.822,0.067)$ & $(0.916,0.0)$ \\
\hline$s_{2}$ & $(0.512,0.34)$ & $(0.749,0.087)$ & $(0.484,0.396)$ & $(0.802,0.091)$ & $(0.624,0.275)$ \\
\hline$s_{3}$ & $(0.171,0.744)$ & $(0.312,0.621)$ & $(0.504,0.432)$ & $(0.695,0.177)$ & $(0.468,0.456)$ \\
\hline$s_{4}$ & $(0.311,0.547)$ & $(0.024,0.873)$ & $(0.376,0.540)$ & $(0.663,0.227)$ & $(0.086,0.635)$ \\
\hline$s_{5}$ & $(0.129,0.772)$ & $(0.239,0.585)$ & $(0.44,0.447)$ & $(0.29,0.567)$ & $(0.0,0.968)$ \\
\hline
\end{tabular}


Such decision matrixes were generated for all 5 experts. Next, the combined decision matrix is created from separate experts matrixes. The elements of the combined matrix are triangular intuitionistic fuzzy numbers $D_{i j}=\left(\left[a_{i j}^{L}, a_{i j}^{M}, a_{i j}^{U}\right],\left[b_{i j}^{L}, b_{i j}^{M}, b_{i j}^{U}\right]\right) . a_{i j}^{L}, a_{i j}^{M}, a_{i j}^{U}$ are the minimum, average and maximum values of 5 experts considering the satisfaction degree of project $s_{i}$ to attribute $r_{j} . b_{i j}^{L}, b_{i j}^{M}, b_{i j}^{U}$ are the minimum, average and maximum values of 5 experts considering the non-satisfaction degree of project $s_{i}$ to attribute $r_{j}$.

According to formula (11), the results of aggregated functions - the generalized weighted averaging operator having 5 exponent $p$ values: $p=0.0 ; 0.01 ; 0.25 ; 0.5 ; 1.0$. are calculated and triangular, interval and point intuitionistic fuzzy numbers of each evaluated project $s_{j}, j=1,2, \ldots, 5$ are obtained. Next, score function values referring to formulas (5)-(7) are calculated finally ranking our projects. Each time, the obtained ranking result is compared with true ranking order $s_{1} \succ s_{2} \succ s_{3} \succ s_{4} \succ s_{5} .500$ Monte Carlo generation experiments have been conducted and repeated 40 times $(500 \times 40=20000)$. The probability of ranking errors has been calculated as a proportion of wrong ranking results amongst all 20000 experiments. The higher is error probability, the less stable is the corresponding generalized weighted averaging operator. It seems to be clear that the more standard deviation $\sigma$ is the higher is the probability of ranking error. The results of the experiment for the initial matrixes of high, medium and low separability in the case of generation by uniform distribution are presented in Table 3. Each row (different $\sigma$ values) contains the least error probability marked in bold font. The most stable generalized average operators for high and medium separability initial matrixes have been interval fuzzy with exponents $p=0.01$ and $p=0.25$, whereas for a low separability initial matrix, triangular and interval generalized average operators with $p=0.01$ have been accepted the most steady.

The dependence of error probability on $\sigma$ taking into consideration various values of exponent $p$ in the case of uniform distribution for intuitionistic interval fuzzy numbers of a high separability initial matrix is depicted in Figure 2.

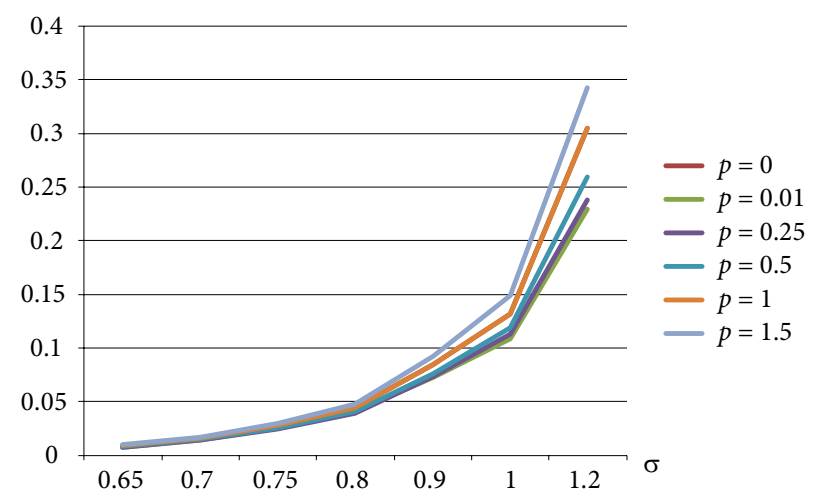

Fig. 2. The dependence of error probability on $\sigma$ considering various values of $p$ in the case of uniform distribution for the intuitionistic interval fuzzy numbers of the high separability initial matrix 
Table 3. The probability of ranking errors considering generalized averaging operators in the case of uniform distribution for high, medium and low separability alternatives

\begin{tabular}{|c|c|c|c|c|c|c|c|c|c|c|c|c|c|c|c|}
\hline \multicolumn{16}{|c|}{ High separability initial matrix } \\
\hline$\sigma$ & 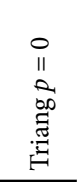 & $\begin{array}{l}0 \\
11 \\
2 \\
\Xi \\
\Xi\end{array}$ & 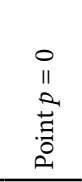 & 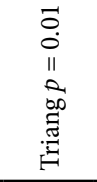 & $\begin{array}{l}\overrightarrow{0} \\
0 \\
\| \\
\| \\
0 \\
\vec{\Xi}\end{array}$ & $\begin{array}{l}\overrightarrow{0} \\
0 \\
11 \\
0 \\
0 \\
.0 \\
0 \\
0\end{array}$ & 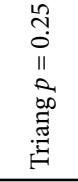 & $\begin{array}{l}\stackrel{10}{0} \\
0 \\
11 \\
0 \\
\stackrel{\Xi}{\Xi}\end{array}$ & 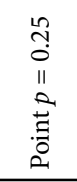 & 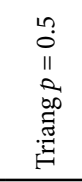 & $\begin{array}{l}n ? \\
0 \\
\| 1 \\
0 \\
\Xi \\
\Xi\end{array}$ & $\begin{array}{l}n ? \\
0 \\
11 \\
0 \\
\vdots \\
0 \\
0 \\
0 \\
0\end{array}$ & 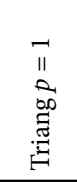 & $\begin{array}{l}\overrightarrow{1} \\
\| \\
\underline{\Xi} \\
\vec{\Xi}\end{array}$ & $\begin{array}{l}\overrightarrow{\|} \\
\| \\
\overrightarrow{0} \\
\overrightarrow{0} \\
0 \\
2\end{array}$ \\
\hline 0.65 & 0.008 & 0.009 & 0.011 & 0.0075 & 0.008 & 0.012 & 0.008 & 0.008 & 0.012 & 0.008 & 0.008 & 0.012 & 0.008 & 0.009 & 0.011 \\
\hline 0.7 & 0.017 & 0.016 & 0.024 & 0.016 & 0.014 & 0.025 & 0.016 & 0.015 & 0.025 & 0.016 & 0.015 & 0.025 & 0.017 & 0.016 & 0.024 \\
\hline 0.75 & 0.028 & 0.028 & 0.041 & 0.027 & 0.026 & 0.042 & 0.027 & 0.025 & 0.041 & 0.027 & 0.026 & 0.041 & 0.028 & 0.028 & 0.041 \\
\hline 0.8 & 0.045 & 0.044 & 0.06 & 0.042 & 0.041 & 0.062 & 0.042 & 0.039 & 0.061 & 0.043 & 0.041 & 0.061 & 0.045 & 0.044 & 0.06 \\
\hline 0.9 & 0.085 & 0.084 & 0.109 & 0.078 & 0.073 & 0.112 & 0.078 & 0.074 & 0.11 & 0.08 & 0.076 & 0.11 & 0.085 & 0.084 & 0.109 \\
\hline 1 & 0.134 & 0.132 & 0.171 & 0.122 & 0.109 & 0.174 & 0.125 & 0.113 & 0.173 & 0.127 & 0.119 & 0.172 & 0.134 & 0.132 & 0.171 \\
\hline 1.2 & 0.295 & 0.305 & 0.333 & 0.238 & 0.229 & 0.337 & 0.252 & 0.238 & 0.334 & 0.267 & 0.259 & 0.334 & 0.295 & 0.305 & 0.333 \\
\hline \multicolumn{16}{|c|}{ Medium separability initial matrix } \\
\hline$\sigma$ & 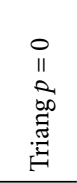 & $\begin{array}{l}0 \\
11 \\
2 \\
\Xi \\
\Xi\end{array}$ & $\begin{array}{c}0 \\
\| 1 \\
2 \\
. \\
.0 \\
0 \\
0\end{array}$ & 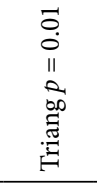 & $\begin{array}{l}\overrightarrow{0} \\
0 \\
\| \\
11 \\
0 \\
\stackrel{\Xi}{\Xi}\end{array}$ & $\begin{array}{c}0 \\
0 \\
0 \\
11 \\
0 \\
.1 \\
.0 \\
0 \\
0\end{array}$ & 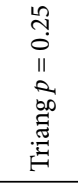 & 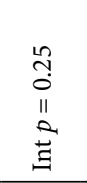 & 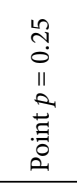 & 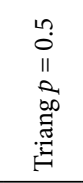 & $\begin{array}{c}n ? \\
0 \\
11 \\
0 \\
\Xi \\
\Xi \\
\Xi\end{array}$ & $\begin{array}{c}n \\
0 \\
11 \\
0 \\
01 \\
0 \\
0 \\
0\end{array}$ & 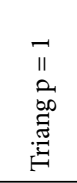 & $\begin{array}{l}\overrightarrow{1} \\
\| \\
\stackrel{2}{\Xi} \\
\Xi\end{array}$ & $\begin{array}{l}\overrightarrow{\|} \\
\| \\
\overrightarrow{0} \\
\stackrel{\Xi}{0} \\
\stackrel{0}{2}\end{array}$ \\
\hline 0.6 & 0.033 & 0.031 & 0.048 & 0.031 & 0.028 & 0.052 & 0.033 & 0.0295 & 0.05 & 0.033 & 0.03 & 0.049 & 0.033 & 0.0314 & 0.048 \\
\hline 0.7 & 0.086 & 0.081 & 0.115 & 0.082 & 0.071 & 0.124 & 0.083 & 0.074 & 0.121 & 0.084 & 0.077 & 0.119 & 0.086 & 0.081 & 0.115 \\
\hline 0.8 & 0.161 & 0.154 & 0.205 & 0.159 & 0.149 & 0.217 & 0.158 & 0.145 & 0.213 & 0.159 & 0.149 & 0.21 & 0.161 & 0.154 & 0.205 \\
\hline 0.9 & 0.249 & 0.244 & 0.302 & 0.240 & 0.223 & 0.314 & 0.244 & 0.226 & 0.312 & 0.246 & 0.232 & 0.308 & 0.25 & 0.244 & 0.302 \\
\hline 1 & 0.350 & 0.341 & 0.412 & 0.317 & 0.289 & 0.425 & 0.33 & 0.302 & 0.421 & 0.338 & 0.316 & 0.418 & 0.35 & 0.341 & 0.412 \\
\hline \multicolumn{16}{|c|}{ Low separability initial matrix } \\
\hline$\sigma$ & 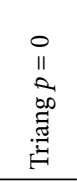 & $\begin{array}{l}0 \\
11 \\
0 \\
\Xi \\
\Xi\end{array}$ & $\begin{array}{l}0 \\
11 \\
0 \\
. \\
.1 \\
0 \\
0\end{array}$ & 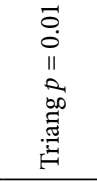 & $\begin{array}{l}\overrightarrow{0} \\
0 \\
11 \\
0 \\
\Xi \\
\Xi\end{array}$ & $\begin{array}{c}0 \\
0 \\
0 \\
11 \\
0 \\
\overrightarrow{1} \\
0 \\
0 \\
0\end{array}$ & 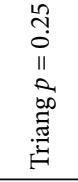 & 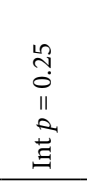 & $\begin{array}{l}0 \\
0 \\
0 \\
11 \\
0 \\
0 \\
.1 \\
0 \\
0 \\
0\end{array}$ & 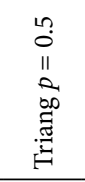 & $\begin{array}{l}10 \\
0 \\
11 \\
0 \\
\Xi \\
\Xi \\
\Xi\end{array}$ & 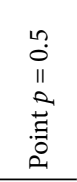 & 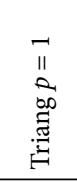 & $\begin{array}{l}\vec{I} \\
\text { I } \\
\vec{\Xi} \\
\underline{\Xi}\end{array}$ & $\begin{array}{l}\overrightarrow{\|} \\
0 \\
\vec{a} \\
\stackrel{\Xi}{0} \\
2\end{array}$ \\
\hline 0.1 & 0.05 & 0.049 & 0.066 & 0.0132 & 0.01285 & 0.02 & 0.018 & 0.0179 & 0.026 & 0.025 & 0.025 & 0.036 & 0.05 & 0.05 & 0.066 \\
\hline 0.15 & 0.115 & 0.115 & 0.143 & 0.0536 & 0.05135 & 0.078 & 0.065 & 0.0614 & 0.089 & 0.078 & 0.076 & 0.103 & 0.115 & 0.115 & 0.143 \\
\hline 0.2 & 0.179 & 0.1816 & 0.206 & 0.1102 & 0.1142 & 0.134 & 0.124 & 0.126 & 0.146 & 0.14 & 0.141 & 0.165 & 0.179 & 0.182 & 0.206 \\
\hline 0.25 & 0.243 & 0.2456 & 0.257 & 0.1738 & 0.1757 & 0.193 & 0.187 & 0.190 & 0.205 & 0.203 & 0.206 & 0.222 & 0.243 & 0.246 & 0.257 \\
\hline 0.3 & 0.298 & 0.302 & 0.31 & 0.234 & 0.2355 & 0.247 & 0.246 & 0.249 & 0.259 & 0.263 & 0.263 & 0.275 & 0.298 & 0.302 & 0.31 \\
\hline 0.4 & 0.374 & 0.3794 & 0.385 & 0.3211 & 0.31935 & 0.339 & 0.332 & 0.332 & 0.349 & 0.345 & 0.346 & 0.358 & 0.374 & 0.379 & 0.385 \\
\hline
\end{tabular}


The dependence of error probability on $p$ taking into consideration various values of $\sigma$ in the case of uniform distribution for the intuitionistic interval fuzzy numbers of the initial separability matrix is presented in Figure 3.

The results of the experiment on high, medium and low separability initial matrixes in the case of generating normal distribution are presented in Table 4 . The most stable generalized averaging operators of the high separability initial matrix include the point generalized averaging operator with exponents $p=0.01$ and $p=0.25$. For medium and low separability initial matrices, the point generalized averaging operator having $p=0.01$ appeared to be the most stable.

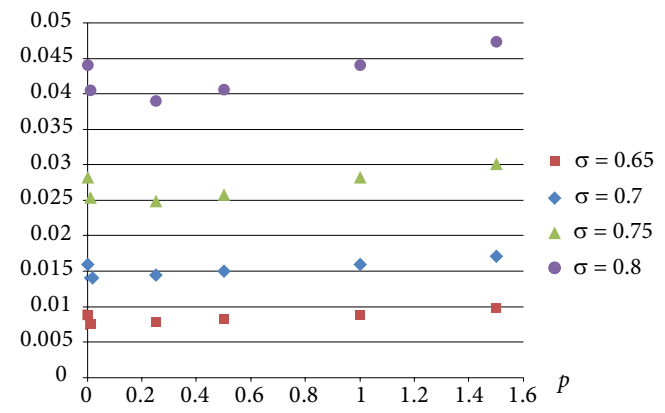

Fig. 3. The dependence of error probability on $p$ considering various values of $\sigma$ in the case of uniform distribution for the intuitionistic interval fuzzy numbers of the high separability initial matrix

The dependence of error probability on $\sigma$ taking into consideration various values of $p$ in the case of normal distribution for the point intuitionistic fuzzy numbers of the low separability initial matrix is shown in Figure 4.

Next, the probability of ranking errors depending on the number of experts will be analyzed. Comparative analysis involving 3, 4 and 5 experts and the medium separability initial matrix has been performed. Different exponent values of generalized weighted averaging operators and various types of intuitionistic fuzzy numbers (triangular, interval and point) have been examined. The chosen numbers of experts are small because, as a rule, hiring

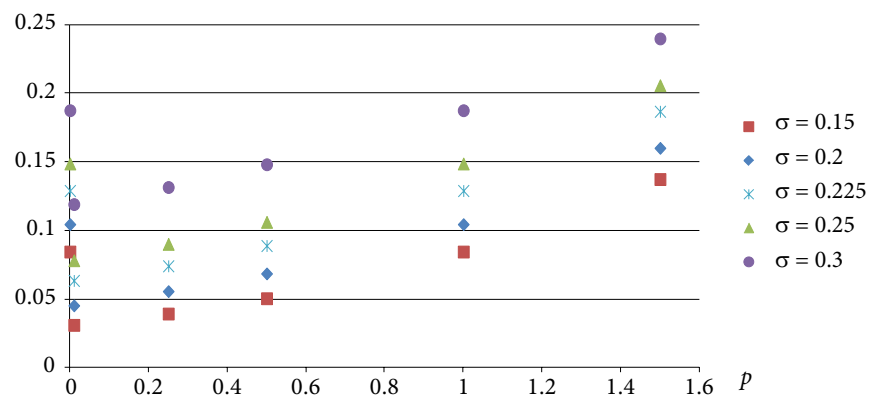

Fig. 4. The dependence of error probability on $p$ considering various values of $\sigma$ in the case of normal distribution for the point interval fuzzy numbers of the low separability initial matrix 
Table 4. The probability of ranking errors for generalized averaging operators in the case of normal distribution for high, medium and low separability alternatives

\begin{tabular}{|c|c|c|c|c|c|c|c|c|c|c|c|c|c|c|c|}
\hline \multicolumn{16}{|c|}{ High separability initial matrix } \\
\hline$\sigma$ & 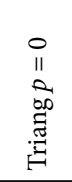 & $\begin{array}{l}0 \\
\| \\
0 \\
\Xi \\
\Xi\end{array}$ & $\begin{array}{l}0 \\
\| 1 \\
2 \\
. \\
. \\
0 \\
0\end{array}$ & 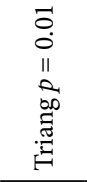 & $\begin{array}{l}\overrightarrow{0} \\
0 \\
11 \\
0 \\
0 \\
\vec{\Xi}\end{array}$ & $\begin{array}{l}\overrightarrow{0} \\
0 \\
11 \\
0 \\
0 \\
0 \\
0 \\
0\end{array}$ & 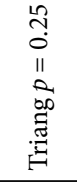 & $\begin{array}{l}\stackrel{1}{1} \\
0 \\
11 \\
0 \\
\stackrel{\Xi}{\Xi}\end{array}$ & 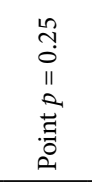 & 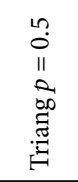 & $\begin{array}{l}n \\
0 \\
11 \\
0 \\
0 \\
\Xi \\
\Xi\end{array}$ & $\begin{array}{c}n \\
0 \\
11 \\
0 \\
0 \\
0 \\
0 \\
0 \\
0\end{array}$ & 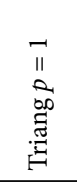 & 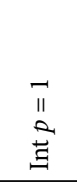 & 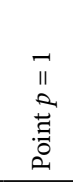 \\
\hline 0.15 & 0.013 & 0.021 & 0.006 & 0.0122 & 0.019 & 0.0055 & 0.012 & 0.019 & 0.0054 & 0.012 & 0.02 & 0.006 & 0.013 & 0.021 & 0.006 \\
\hline 0.2 & 0.085 & 0.113 & 0.055 & 0.083 & 0.113 & 0.0528 & 0.081 & 0.108 & 0.053 & 0.082 & 0.109 & 0.054 & 0.085 & 0.113 & 0.055 \\
\hline 0.25 & 0.206 & 0.249 & 0.153 & 0.216 & 0.282 & 0.1476 & 0.202 & 0.250 & 0.149 & 0.201 & 0.246 & 0.149 & 0.206 & 0.25 & 0.153 \\
\hline 0.3 & 0.332 & 0.381 & 0.268 & 0.348 & 0.438 & 0.2625 & 0.328 & 0.384 & 0.264 & 0.325 & 0.378 & 0.264 & 0.332 & 0.381 & 0.268 \\
\hline \multicolumn{16}{|c|}{ Medium separability initial matrix } \\
\hline$\sigma$ & 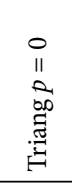 & $\begin{array}{l}0 \\
11 \\
2 \\
\Xi \\
\Xi\end{array}$ & $\begin{array}{l}0 \\
\| \\
2 \\
2 \\
. \\
0 \\
0 \\
0\end{array}$ & 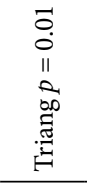 & $\begin{array}{l}\overrightarrow{0} \\
0 \\
\| \\
\| \\
e \\
\vec{\Xi}\end{array}$ & $\begin{array}{c}0 \\
0 \\
0 \\
11 \\
0 \\
0.1 \\
0 \\
0 \\
0\end{array}$ & 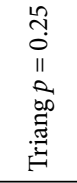 & 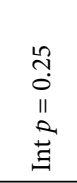 & $\begin{array}{l}10 \\
1 \\
0 \\
11 \\
0 \\
0 \\
. \\
0 \\
0 \\
0\end{array}$ & 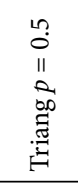 & 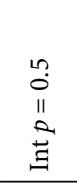 & 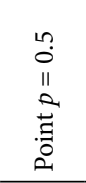 & 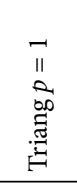 & $\begin{array}{l}\vec{I} \\
\stackrel{2}{\Xi} \\
\vec{\Xi}\end{array}$ & $\begin{array}{l}\overrightarrow{1} \\
\| \\
2 \\
\vec{\Xi} \\
. \\
0\end{array}$ \\
\hline 0.1 & 0.008 & 0.014 & 0.003 & 0.008 & 0.013 & 0.0032 & 0.008 & 0.013 & 0.0033 & 0.008 & 0.013 & 0.0034 & 0.008 & 0.014 & 0.003 \\
\hline 0.15 & 0.123 & 0.154 & 0.08 & 0.114 & 0.149 & 0.077 & 0.114 & 0.146 & 0.078 & 0.116 & 0.148 & 0.078 & 0.123 & 0.154 & 0.08 \\
\hline 0.2 & 0.324 & 0.368 & 0.256 & 0.316 & 0.368 & 0.248 & 0.311 & 0.356 & 0.249 & 0.315 & 0.361 & 0.251 & 0.324 & 0.368 & 0.256 \\
\hline 0.25 & 0.483 & 0.527 & 0.415 & 0.494 & 0.556 & 0.409 & 0.476 & 0.523 & 0.409 & 0.476 & 0.521 & 0.41 & 0.483 & 0.527 & 0.415 \\
\hline \multicolumn{16}{|c|}{ Low separability initial matrix } \\
\hline$\sigma$ & 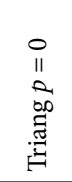 & $\begin{array}{l}0 \\
\| \\
Q \\
\Xi \\
\Xi\end{array}$ & $\begin{array}{l}0 \\
\| 1 \\
0 \\
. \\
. \\
0 \\
0 \\
0\end{array}$ & 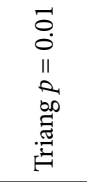 & $\begin{array}{l}\overrightarrow{0} \\
0 \\
\| \\
\underline{0} \\
\ddot{\Xi}\end{array}$ & $\begin{array}{l}0 \\
0 \\
0 \\
11 \\
0 \\
.1 \\
0 \\
0 \\
0\end{array}$ & 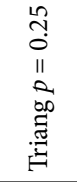 & $\begin{array}{l}\stackrel{1}{n} \\
0 \\
\| \\
\| \\
0 \\
0 \\
\Xi \\
\Xi\end{array}$ & $\begin{array}{l}\stackrel{1}{n} \\
0 \\
11 \\
0 \\
0.0 \\
.0 \\
0 \\
0\end{array}$ & 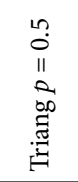 & $\begin{array}{l}10 \\
0 \\
11 \\
0 \\
\vdots \\
\Xi\end{array}$ & $\begin{array}{l}n \\
0 \\
11 \\
0 \\
.0 \\
.07 \\
0\end{array}$ & 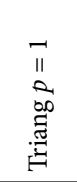 & 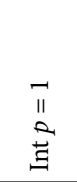 & $\begin{array}{l}\overrightarrow{11} \\
\| \\
2 \\
\vec{\Xi} \\
0 \\
0\end{array}$ \\
\hline 0.03 & 0.109 & 0.121 & 0.104 & 0.046 & 0.055 & 0.045 & 0.056 & 0.065 & 0.056 & 0.07 & 0.079 & 0.069 & 0.109 & 0.121 & 0.104 \\
\hline 0.035 & 0.136 & 0.151 & 0.129 & 0.069 & 0.081 & 0.063 & 0.08 & 0.092 & 0.074 & 0.094 & 0.108 & 0.089 & 0.136 & 0.151 & 0.129 \\
\hline 0.04 & 0.161 & 0.178 & 0.149 & 0.089 & 0.106 & 0.078 & 0.102 & 0.118 & 0.09 & 0.118 & 0.134 & 0.106 & 0.161 & 0.178 & 0.149 \\
\hline 0.05 & 0.208 & 0.231 & 0.188 & 0.138 & 0.161 & 0.119 & 0.152 & 0.173 & 0.131 & 0.166 & 0.19 & 0.148 & 0.208 & 0.231 & 0.188 \\
\hline
\end{tabular}

experts is rather expensive. Table 5 indicates the probability of ranking errors considering generalized averaging operators with uniform distribution in the cases of 3, 4 and 5 experts. For each row, the least probability of error is marked in bold font. The expectable result has been obtained - the bigger is the number of experts, the lower is the probability of ranking errors. Trends are very similar in the cases of 3,4 and 5 experts - the most stable generalized averaging operators almost for all $\sigma$ values have been those with a fuzzy interval and exponent $p=0.01$. 
Table 5. The probability of ranking errors for generalized averaging operators with uniform distribution and the medium separability initial matrix in the cases of 3,4 and 5 experts

\begin{tabular}{|c|c|c|c|c|c|c|c|c|c|c|c|c|c|c|c|}
\hline \multicolumn{16}{|c|}{3 experts } \\
\hline$\sigma$ & 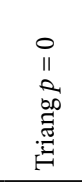 & $\begin{array}{l}0 \\
11 \\
0 \\
\underline{\Xi} \\
\Xi\end{array}$ & 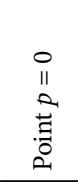 & 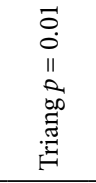 & 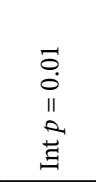 & $\begin{array}{l}\overrightarrow{0} \\
0 \\
0 \\
11 \\
0 \\
0 \\
. \\
0 \\
0 \\
0\end{array}$ & 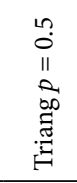 & 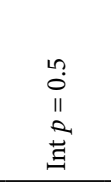 & $\begin{array}{l}n \\
0 \\
11 \\
0 \\
. \\
.0 \\
0 \\
0\end{array}$ & 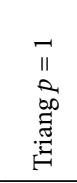 & $\begin{array}{l}\overrightarrow{1} \\
11 \\
2 \\
\Xi \\
\end{array}$ & 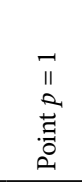 & 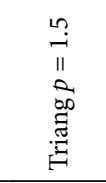 & 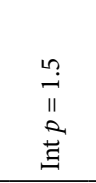 & 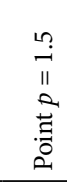 \\
\hline 0.5 & 0.095 & 0.0959 & 0.102 & 0.0962 & 0.0957 & 0.105 & 0.096 & 0.0962 & 0.103 & 0.095 & 0.0959 & 0.102 & 0.0942 & 0.0966 & 0.101 \\
\hline 0.6 & 0.1775 & 50.1733 & 0.199 & 0.1684 & 0.1577 & 0.206 & 0.176 & 0.1697 & 0.202 & 0.178 & 0.1733 & 0.199 & 0.1767 & 0.1751 & 0.195 \\
\hline 0.7 & 0.2887 & 70.281 & 0.317 & 0.2746 & 0.2574 & 0.327 & 0.287 & 0.2751 & 0.321 & 0.289 & 0.281 & 0.317 & 0.2894 & 0.2848 & 0.314 \\
\hline 0.8 & 0.3921 & 10.3833 & 0.425 & 0.3755 & 0.3578 & 0.438 & 0.388 & 0.3748 & 0.431 & 0.392 & 0.3833 & 0.425 & 0.3942 & 0.3882 & 0.42 \\
\hline \multicolumn{16}{|c|}{4 experts } \\
\hline$\sigma$ & 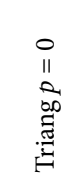 & $\begin{array}{l}0 \\
11 \\
0 \\
\pm \\
\underline{E}\end{array}$ & $\begin{array}{c}0 \\
\| \\
2 \\
0 \\
.1 \\
0 \\
0\end{array}$ & 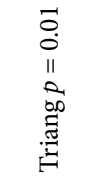 & 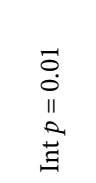 & $\begin{array}{l}0 \\
0 \\
0 \\
11 \\
2 \\
0 \\
0 \\
0 \\
0 \\
0\end{array}$ & 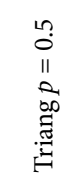 & 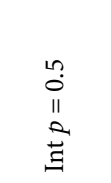 & 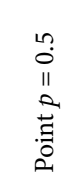 & 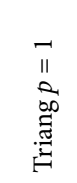 & $\begin{array}{l}\overrightarrow{1} \\
\mathbb{Z} \\
\vec{\Xi}\end{array}$ & 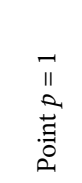 & 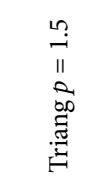 & 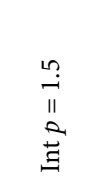 & 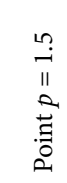 \\
\hline 0.5 & 0.0319 & $\begin{array}{l}9 \\
9\end{array}$ & 0.04 & 0.0326 & 0.0301 & 0.042 & 0.032 & 0.0298 & 0.04 & 0.032 & 0.03 & 0.04 & 0.0314 & 0.0307 & 0.039 \\
\hline 0.6 & 0.0782 & 20.0748 & 0.1 & 0.0751 & 0.0675 & 0.108 & 0.078 & 0.0728 & 0.104 & 0.078 & 0.0748 & 0.1 & 0.0780 & 0.0767 & 0.096 \\
\hline 0.7 & 0.155 & 0.1469 & 0.189 & 0.1457 & 0.1317 & 0.202 & 0.153 & 0.1423 & 0.196 & 0.155 & 0.1469 & 0.189 & 0.1562 & 0.1493 & 0.185 \\
\hline 0.8 & 0.2561 & 10.24725 & 0.299 & 0.2468 & 0.2322 & 0.312 & 0.254 & 0.2404 & 0.306 & 0.256 & 0.2473 & 0.299 & 0.2577 & 0.2523 & 0.294 \\
\hline \multicolumn{16}{|c|}{5 experts } \\
\hline$\sigma$ & 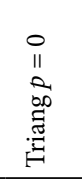 & $\begin{array}{l}0 \\
11 \\
0 \\
\Xi \\
\Xi\end{array}$ & 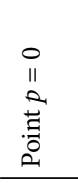 & 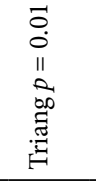 & $\begin{array}{l}\overrightarrow{0} \\
0 \\
\| \\
0 \\
0 \\
\vec{\Xi}\end{array}$ & $\begin{array}{l}0 \\
0 \\
0 \\
11 \\
2 \\
0.1 \\
.0 \\
0 \\
0\end{array}$ & 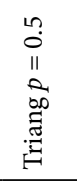 & $\begin{array}{l}n \\
0 \\
11 \\
0 \\
\Xi \\
\Xi\end{array}$ & 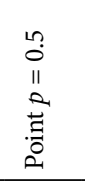 & 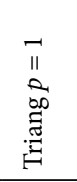 & $\begin{array}{l}\overrightarrow{1} \\
\text { Q } \\
\vec{\Xi}\end{array}$ & $\begin{array}{l}\vec{I} \\
\text { on } \\
\vec{\Xi} \\
.0 \\
0\end{array}$ & 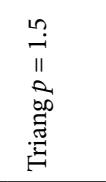 & $\begin{array}{l}\stackrel{n}{n} \\
11 \\
2 \\
\underline{\Xi}\end{array}$ & 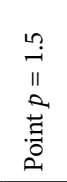 \\
\hline 0.5 & 0.0104 & 40.0097 & 0.014 & 0.0107 & 0.0095 & 0.015 & 0.011 & 0.0095 & 0.014 & 0.01 & 0.0097 & 70.014 & 0.0099 & 0.0098 & 0.013 \\
\hline 0.6 & 0.0331 & 10.0314 & 0.048 & 0.0313 & 0.0280 & 0.052 & 0.033 & 0.0304 & 0.049 & 0.033 & 0.0314 & 0.048 & 0.0338 & 0.0325 & 0.046 \\
\hline 0.7 & 0.0864 & 40.08095 & 0.115 & 0.0817 & 0.0710 & 0.124 & 0.084 & 0.07675 & 0.119 & 0.086 & 0.081 & 0.115 & 0.0873 & 0.0844 & 0.111 \\
\hline 0.8 & 0.1612 & 20.15405 & 0.205 & 0.1586 & 0.1485 & 0.217 & 0.159 & 0.1488 & 0.21 & 0.161 & 0.1541 & 0.205 & 0.1625 & 0.1604 & 0.2 \\
\hline
\end{tabular}

Table 6 shows the probability of ranking errors for generalized averaging operators with normal distribution in the cases of 3,4 and 5 experts and the medium separability initial matrix. Likewise in the case of uniform distribution, a higher number of experts results in the lower probability of ranking errors. In all cases, the most stable values of generalized averaging operators have been those including a fuzzy point with exponent $p=0.01$.

Figure 5 shows two graphs of the dependence of error probability on $\sigma$ regarding various values of $p$ in the cases of uniform and normal distribution and the medium separability initial matrix. 
Table 6 . The probability of ranking errors for generalized averaging operators with normal distribution and the medium separability initial matrix in the cases of 3, 4 and 5 experts

\begin{tabular}{|c|c|c|c|c|c|c|c|c|c|c|c|c|c|c|c|}
\hline \multicolumn{16}{|c|}{3 experts } \\
\hline$\sigma$ & 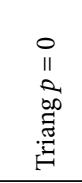 & 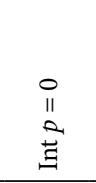 & $\begin{array}{l}0 \\
\| \\
0 \\
0.1 \\
.0 \\
0 \\
0\end{array}$ & 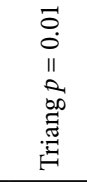 & $\begin{array}{l}\overrightarrow{0} \\
0 \\
11 \\
0 \\
\pm \\
\Xi\end{array}$ & $\begin{array}{l}\overrightarrow{0} \\
0 \\
11 \\
0 \\
0 \\
.1 \\
0 \\
0\end{array}$ & 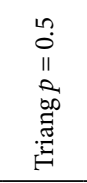 & $\begin{array}{l}n \\
0 \\
11 \\
0 \\
\vdots \\
\Xi\end{array}$ & $\begin{array}{c}n ? \\
0 \\
11 \\
0 \\
0 \\
0 \\
0 \\
0\end{array}$ & 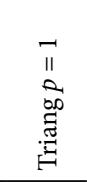 & $\begin{array}{l}\overrightarrow{\|} \\
\stackrel{11}{ \pm} \\
\underline{\Xi}\end{array}$ & $\begin{array}{l}-1 \\
11 \\
0 \\
. \\
0 \\
0 \\
0\end{array}$ & 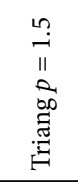 & 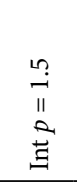 & 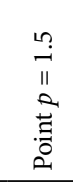 \\
\hline 0.1 & 0.0259 & 0.0334 & 0.018 & 0.0246 & 0.0326 & 0.0169 & 0.025 & 0.032 & 0.0173 & 0.026 & 0.033 & 0.018 & 0.027 & 0.035 & 0.018 \\
\hline 0.15 & 0.2154 & 0.242 & 0.178 & 0.2034 & 0.2301 & 0.170 & 0.208 & 0.234 & 0.1739 & 0.215 & 0.242 & 0.178 & 0.222 & 0.25 & 0.181 \\
\hline 0.2 & 0.4348 & 0.4676 & 0.389 & 0.4181 & 0.4487 & 0.3812 & 0.425 & 0.455 & 0.384 & 0.435 & 0.468 & 0.389 & 0.445 & 0.478 & 0.396 \\
\hline 0.25 & 0.595 & 0.6198 & 0.554 & 0.5825 & 0.6144 & 0.5479 & 0.586 & 0.609 & 0.5505 & 0.595 & 0.62 & 0.554 & 0.605 & 0.628 & 0.56 \\
\hline \multicolumn{16}{|c|}{4 experts } \\
\hline$\sigma$ & 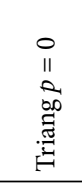 & $\begin{array}{l}0 \\
11 \\
0 \\
\Xi \\
\Xi\end{array}$ & $\begin{array}{l}0 \\
\| 1 \\
2 \\
0 \\
.1 \\
0 \\
0.1\end{array}$ & 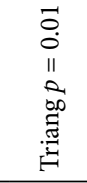 & $\begin{array}{l}\overrightarrow{0} \\
0 \\
\| \\
\| \\
0 \\
\vec{\Xi}\end{array}$ & $\begin{array}{l}0 \\
0 \\
0 \\
11 \\
0 \\
0 \\
.0 \\
0 \\
0 \\
0\end{array}$ & 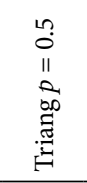 & $\begin{array}{l}n \\
0 \\
\| 1 \\
0 \\
0 \\
\Xi\end{array}$ & $\begin{array}{l}n \\
0 \\
11 \\
0 \\
0.1 \\
0 \\
0 \\
0\end{array}$ & 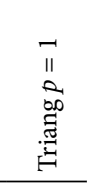 & $\begin{array}{l}\vec{I} \\
2 \\
\underline{E} \\
\underline{E}\end{array}$ & 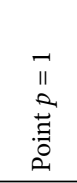 & 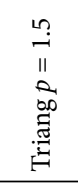 & $\begin{array}{l}\stackrel{n}{n} \\
\text { II } \\
2 \\
\stackrel{\Xi}{\Xi}\end{array}$ & $\begin{array}{l}n \\
11 \\
11 \\
0 \\
.1 \\
0 \\
0 \\
0\end{array}$ \\
\hline 0.1 & 0.0151 & 0.0229 & 0.007 & 0.0144 & 0.021 & 0.0069 & 0.007 & 0.015 & 0.022 & 0.0071 & 0.015 & 0.023 & 0.007 & 0.016 & 0.024 \\
\hline 0.15 & 0.1565 & 0.1901 & 0.114 & 0.147 & 0.1811 & 0.1099 & 0.1107 & 0.151 & 0.182 & 0.1116 & 0.156 & 0.19 & 0.114 & 0.163 & 0.197 \\
\hline 0.2 & 0.368 & 0.4041 & 0.31 & 0.354 & 0.3951 & 0.3019 & 0.3037 & 0.358 & 0.394 & 0.3058 & 0.368 & 0.404 & 0.31 & 0.377 & 0.414 \\
\hline 0.25 & 0.5328 & 0.567 & 0.482 & 0.5343 & 0.5824 & 0.4729 & 0.4738 & 0.525 & 0.56 & 0.476 & 0.533 & 0.567 & 0.482 & 0.541 & 0.577 \\
\hline \multicolumn{16}{|c|}{5 experts } \\
\hline$\sigma$ & 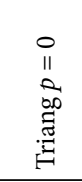 & $\begin{array}{l}0 \\
11 \\
2 \\
\Xi \\
\Xi\end{array}$ & $\begin{array}{l}0 \\
11 \\
0 \\
0 \\
.1 \\
0 \\
0\end{array}$ & 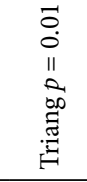 & $\begin{array}{l}\overrightarrow{0} \\
0 \\
11 \\
0 \\
0 \\
\\
\end{array}$ & $\begin{array}{l}0 \\
0 \\
0 \\
11 \\
2 \\
0.1 \\
.0 \\
0 \\
0 \\
0.1\end{array}$ & 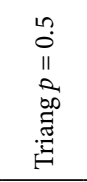 & $\begin{array}{l}n ? \\
0 \\
11 \\
0 \\
\ddot{\Xi}\end{array}$ & 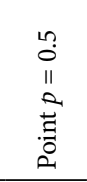 & 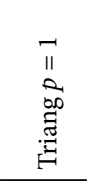 & $\begin{array}{l}\vec{I} \\
2 \\
\vec{\Xi}\end{array}$ & $\begin{array}{l}\overrightarrow{\|} \\
0 \\
0 \\
. \\
0 \\
0\end{array}$ & 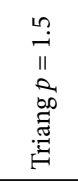 & $\begin{array}{l}\stackrel{n}{1} \\
\| 1 \\
2 \\
\underline{\Xi}\end{array}$ & 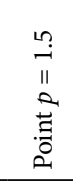 \\
\hline 0.1 & 0.0083 & 0.0141 & 0.003 & 0.0077 & 0.01325 & 0.0032 & 0.008 & 0.013 & 0.0034 & 0.008 & 0.014 & 0.003 & 0.009 & 0.015 & 0.003 \\
\hline 0.150 & 0.12265 & 0.1543 & 0.08 & 0.1143 & 0.14895 & 0.0768 & 0.116 & 0.148 & 0.0785 & 0.123 & 0.154 & 0.08 & 0.127 & 0.16 & 0.082 \\
\hline 0.2 & 0.3236 & 0.3683 & 0.256 & 0.316 & 0.36845 & 0.2486 & 0.315 & 0.361 & 0.2515 & 0.324 & 0.368 & 0.256 & 0.332 & 0.378 & 0.26 \\
\hline 0.25 & 0.4828 & 0.5266 & 0.415 & 0.4935 & 0.55595 & 0.4092 & 0.476 & 0.521 & 0.410 & 0.483 & 0.527 & 0.415 & 0.488 & 0.533 & 0.421 \\
\hline
\end{tabular}

The results of the conducted research have disclosed that the least probability of ranking errors has not been noticed neither as regards arithmetic $(p=1)$ nor geometric averaging operators $(p=0)$ in the case of 5 alternatives and 5 criteria for 3, 4 and 5 experts when analyzing normally and uniformly distributed IFNs. Thus, the advantage of generalized averaging operators is a minor error in ranking probability. The following numerical example will show that in a marginal case, when at least for one alternative and one criteria $\mu_{a}=(0 ; 0 ; 0)$, the weighted geometric averaging operator will assign the lowest rank to this alternative despite 
a)

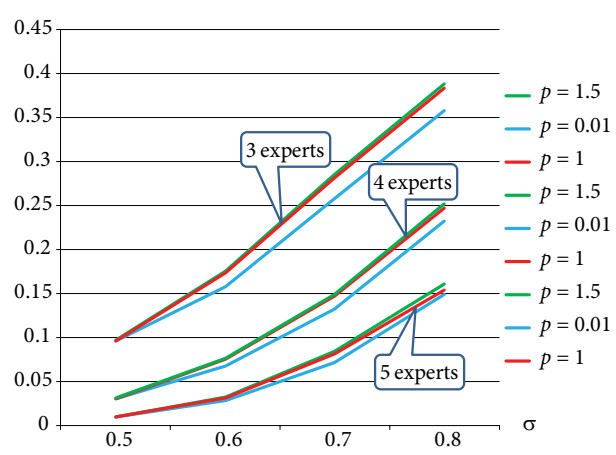

b)

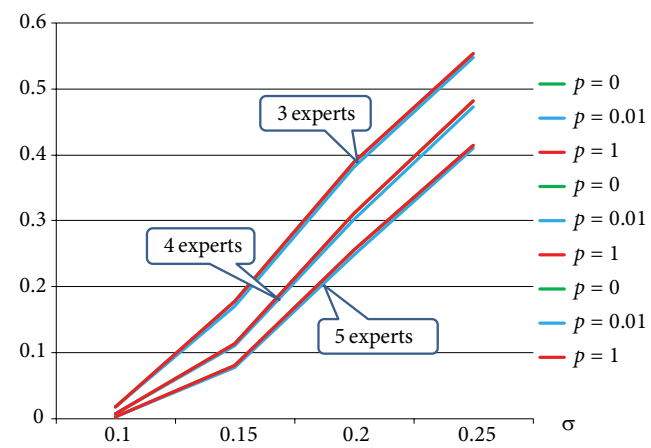

Fig. 5. The dependence of error probability on $\sigma$ considering various values of $p$ and 3, 4 and 5 experts in the cases of uniform distribution for intuitionistic interval fuzzy numbers (a) and normal distribution for intuitionistic point fuzzy numbers (b)

of the values of other elements of the decision matrix. On the other hand, when at least for one alternative and one criteria $\mu_{a}=(1 ; 1 ; 1)$, the weighted arithmetic averaging operator will assign the highest rank to this alternative despite of the values of other elements of the decision matrix. Thus, in such marginal cases, the weighted geometric averaging operator and the weighted arithmetic averaging operator become insensitive and inappropriate.

\section{An example of data fuzzification and FMCDM application}

Suppose we have $n$ indicators $x_{j} \in[0 ;+\infty)$ used for comparing alternatives $A^{1}=\left(x_{1}^{1}, x_{2}^{1}, \ldots, x_{n}^{1}\right)$ and $A^{2}=\left(x_{1}^{2}, x_{2}^{2}, \ldots, x_{n}^{2}\right)$ :

$$
A^{1} \prec A^{2} \text { if }(\forall j) x_{j}^{1} \leq x_{j}^{2} .
$$

Let $x_{j}$ be triangular fuzzy numbers $x_{j}=\left(x_{j, L}, x_{j, M}, x_{j, U}\right), x_{j, L} \leq x_{j, M} \leq x_{j, U}$. If we have $m$ alternatives $A^{i}, i=1,2, \ldots, m$, the decision matrix is as follows ${ }^{2}$ :

$$
D=\left(\begin{array}{cccc}
\left(x_{1, L}^{1}, x_{1, M}^{1}, x_{1, U}^{1}\right) & \left(x_{1, L}^{2}, x_{1, M}^{2}, x_{1, U}^{2}\right) & \ldots & \left(x_{1, L}^{m}, x_{1, M}^{m}, x_{1, U}^{m}\right) \\
\left(x_{2, L}^{1}, x_{2, M}^{1}, x_{2, U}^{1}\right) & \left(x_{2, L}^{2}, x_{2, M}^{2}, x_{2, U}^{2}\right) & \ldots & \left(x_{2, L}^{m}, x_{2, M}^{m}, x_{2, U}^{m}\right) \\
\ldots & \ldots & \ldots & \ldots \\
\left(x_{n, L}^{1}, x_{n, M}^{1}, x_{n, U}^{1}\right) & \left(x_{n, L}^{2}, x_{n, M}^{2}, x_{n, U}^{2}\right) & \ldots & \left(x_{n, L}^{m}, x_{n, M}^{m}, x_{n, U}^{m}\right)
\end{array}\right)
$$

Thus, numbers $m_{j}$ and $M_{j}$ can be chosen: $(\forall i) m_{j} \leq x_{j, L}^{i}, x_{j, U}^{i} \leq M_{j}$. Numbers $m_{j}$ and $M_{j}$ could be either theoretical bounds of indicators $x_{j}$ or quantities obtained from empirical 
data, for example, $m_{j}=\min _{i} x_{j, L}^{i}, M_{j}=\max _{i} x_{j, U}^{i}$. Normalized triangular fuzzy numbers are constructed as triplets $\mu_{j} \stackrel{i}{=}\left(\mu_{j, L}, \mu_{j, M}, \mu_{j, U}^{i}\right)$ :

$$
\mu_{j, p}=\frac{x_{j, p}-m_{j}}{M_{j}-m_{j}}, p=L, M, U .
$$

It seems to be clear that $0 \leq \mu_{j, L}, \mu_{j, M}, \mu_{j, U} \leq 1$ when indicator $x_{j}$ has a direct relationship with alternatives $A^{i}$. Let's agree that $\mu_{j, L}=\mu_{j, M}=\mu_{j, U}$ if $m_{j}=M_{j}$. Corresponding normalized values $\mu_{j, L}^{i}, \mu_{j, M}^{i}, \mu_{j, U}^{i}$ are the lower, modal and upper degrees of the adequacy of alternative $A^{i}$ to indicator (criteria) $x_{j}$.

Remark. In the case when indicator $x_{j^{*}}$ has an opposite relationship with alternatives $A^{i}$, i.e. $A^{1} \prec A^{2}$, when

$(\forall j \in J) x_{j}^{1} \leq x_{j}^{2} \&\left(\forall j^{*} \in J^{*}\right) x_{j^{*}}^{1} \geq x_{j^{*}}^{2}, J \cup J^{*}=\{1,2, \ldots n\}, J \cap J^{*}=\varnothing$, the values of thelower, modal and upper degrees of the adequacy of alternative $A^{i}$ to indicator $x_{j^{*}}$ are constructed as follows:

$$
\mu_{j^{*}, p}=\frac{M_{j^{*}}-x_{j^{*}, p}}{M_{j^{*}}-m_{j^{*}}}, p=L, M, U .
$$

Further, an example (Antuchevičienè et al. 2010, 2011) where a decision on possible redevelopment alternatives to derelict rural buildings must be chosen from 3 alternatives will be analyzed: the reconstruction of rural buildings and adapting them to production (or commercial) activities (alternative $A^{1}$ ), improving and using them for farming (alternative $A^{2}$ ) or dismantling and recycling demolition waste materials (alternative $A^{3}$ ). Three groups of criteria (sustainability indicators) describing the suggested alternatives were applied: the existing state $\left(x_{1}-x_{6}\right)$, development possibilities $\left(x_{7}-x_{11}\right)$ and environmental impact $\left(x_{12}-x_{15}\right)$ :

$x_{1}$ - average soil fertility in the area (points); $x_{2}$ - the quality of life of the local population (points); $x_{3}$ - population activity index (\%); $x_{4}$ - GDP proportion with respect to the average GDP of the country (\%); $x_{5}-$ material investment in the area (Lt per resident); $x_{6}-$ foreign investment in the area (Lt $\times 10^{3}$ per resident);

$x_{7}$ - building redevelopment costs $\left(\operatorname{Lt} \times 10^{6}\right) ; x_{8}$ - an increase in the income of the local population $\left(\mathrm{Lt} \times 10^{6}\right.$ per year);

$x_{9}$ - an increase in sales in the area (\%); $x_{10}$ - an increase in employment in the area (\%); $x_{11}$ - state income from business and property taxes (Lt $\times 10^{6}$ per year); $x_{12}$ - business outlook; $x_{13}$-difficulties in changing the original purpose of a site; $x_{14}$ - the degree of contamination; $x_{15}$ - the attractiveness of the countryside (i.e. image, landscape, etc).

Among the criteria, considered $x_{2}, x_{7}, x_{13}, x_{14}$ are associated with cost/loss and therefore their lower value is better while the remaining criteria are associated with benefit and their higher value is better. Hence, $J^{\star}=\{2,7,13,14\}, J=\{1,3,4,5,6,8,9,10,11,12,15\}$. Three decision matrixes are given for three regions according to the concept of the spatial development of the country: the areas of active development, the areas of regressing development and 'buffer' areas. These matrixes are presented in Table 7. 
Table 7. Initial decision matrixes for the areas of active development, the areas of regressing development and 'buffer' areas

\begin{tabular}{|c|c|c|c|c|}
\hline $\begin{array}{c}\text { Criteria } \\
\text { (indicator) }\end{array}$ & $\begin{array}{l}\text { Weight of } \\
\text { indicator }\end{array}$ & Alternative $A^{1}$ & Alternative $A^{2}$ & Alternative $A^{3}$ \\
\hline \multicolumn{5}{|c|}{ Areas of active development } \\
\hline$x_{1}$ & 0,0600 & $(30.9 ; 39.9 ; 50.0)$ & $(30.9 ; 39.9 ; 50.0)$ & $(30.9 ; 39.9 ; 50.0)$ \\
\hline$x_{2}$ & 0,0727 & $(39.3 ; 31.7 ; 23.1)$ & $(39.3 ; 31.7 ; 23.1)$ & $(39.3 ; 31.7 ; 23.1)$ \\
\hline$x_{3}$ & 0,0747 & $(39.8 ; 51.7 ; 68.1)$ & $(39.8 ; 51.7 ; 68.1)$ & $(39.8 ; 51.7 ; 68.1)$ \\
\hline$x_{4}$ & 0,0627 & $(73.9 ; 98.4 ; 137.3)$ & $(73.9 ; 98.4 ; 137.3)$ & $(73.9 ; 98.4 ; 137.3)$ \\
\hline$x_{5}$ & 0,0673 & $(552.0 ; 1304.0 ; 3561.0)$ & $(552.0 ; 1304.0 ; 3561.0)$ & $(552.0 ; 1304.0 ; 3561.0)$ \\
\hline$x_{6}$ & 0,0627 & $(73.2 ; 1028.7 ; 4160.0)$ & $(73.2 ; 1028.7 ; 4160.0)$ & $(73.2 ; 1028.7 ; 4160.0)$ \\
\hline$x_{7}$ & 0,0667 & $(766.1 ; 273.6 ; 35.6)$ & $(144.9 ; 59.4 ; 28.5)$ & $(20.2 ; 14.4 ; 8.6)$ \\
\hline$x_{8}$ & 0,0667 & $(31.1 ; 69.1 ; 241.9)$ & $(7.8 ; 25.9 ; 48.4)$ & $(0.3 ; 0.4 ; 1.2)$ \\
\hline$x_{9}$ & 0,0667 & $(2.3 ; 14.0 ; 39.1)$ & $(0.7 ; 2.2 ; 4.7)$ & $(0 ; 0 ; 0)$ \\
\hline$x_{10}$ & 0,0667 & $(2.1 ; 3.4 ; 9.6)$ & $(0.5 ; 1.7 ; 2.4)$ & $(0 ; 0 ; 0)$ \\
\hline$x_{11}$ & 0,0667 & $(8.6 ; 21.6 ; 50.4)$ & $(2.2 ; 5.4 ; 10.1)$ & $(0.1 ; 0.2 ; 0.5)$ \\
\hline$x_{12}$ & 0,0667 & $(0.8 ; 0.9 ; 1)$ & $(0.2 ; 0.3 ; 0.4)$ & $(0.6 ; 0.7 ; 0.8)$ \\
\hline$x_{13}$ & 0,0667 & $(1 ; 0.9 ; 0.8)$ & $(0.2 ; 0.1 ; 0)$ & $(0.8 ; 0.7 ; 0.6)$ \\
\hline$x_{14}$ & 0,0667 & $(0.8 ; 0.7 ; 0.6)$ & $(0.6 ; 0.5 ; 0.4)$ & $(0.2 ; 0.1 ; 0)$ \\
\hline$x_{15}$ & 0,0667 & $(0.6 ; 0.7 ; 0.8)$ & $(0.4 ; 0.5 ; 0.6)$ & $(0.2 ; 0.3 ; 0.4)$ \\
\hline \multicolumn{5}{|c|}{ Areas of regressing development } \\
\hline$x_{1}$ & 0,0740 & $(31.1 ; 34.8 ; 44.3)$ & $(31.1 ; 34.8 ; 44.3)$ & $(31.1 ; 34.8 ; 44.3)$ \\
\hline$x_{2}$ & 0,0613 & $(37.78 ; 29.1 ; 20.78)$ & $(37.78 ; 29.1 ; 20.78)$ & $(37.78 ; 29.1 ; 20.78)$ \\
\hline$x_{3}$ & 0,0626 & $(47.1 ; 55.9 ; 66.2)$ & $(47.1 ; 55.9 ; 66.2)$ & $(47.1 ; 55.9 ; 66.2)$ \\
\hline$x_{4}$ & 0,0613 & $(79.5 ; 94.7 ; 137.3)$ & $(79.5 ; 94.7 ; 137.3)$ & $(79.5 ; 94.7 ; 137.3)$ \\
\hline$x_{5}$ & 0,0740 & $(212.0 ; 962.9 ; 3504.0)$ & $(212.0 ; 962.9 ; 3504.0)$ & $(212.0 ; 962.9 ; 3504.0)$ \\
\hline$x_{6}$ & 0,0673 & $(8.14 ; 833.1 ; 3550.5)$ & $(8.14 ; 833.1 ; 3550.5)$ & $(8.14 ; 833.1 ; 3550.5)$ \\
\hline$x_{7}$ & 0,0667 & $(667.3 ; 238.6 ; 31.0)$ & $(100.1 ; 51.8 ; 24.8)$ & $(17.6 ; 12.6 ; 7.6)$ \\
\hline$x_{8}$ & 0,0667 & $(27.1 ; 60.3 ; 210.7)$ & $(6.8 ; 22.6 ; 42.1)$ & $(0.2 ; 0.4 ; 1.1)$ \\
\hline$x_{9}$ & 0,0667 & $(12.7 ; 75.8 ; 212.1)$ & $(3.6 ; 12.1 ; 25.4)$ & $(0 ; 0 ; 0)$ \\
\hline$x_{10}$ & 0,0667 & $(1.6 ; 2.6 ; 7.3)$ & $(0.4 ; 1.3 ; 1.8)$ & $(0 ; 0 ; 0)$ \\
\hline$x_{11}$ & 0,0667 & $(7.5 ; 22.0 ; 43.9)$ & $(1.9 ; 4.7 ; 8.8)$ & $(0.1 ; 0.2 ; 0.4)$ \\
\hline$x_{12}$ & 0,0667 & $(0.2 ; 0.3 ; 0.4)$ & $(0.4 ; 0.5 ; 0.6)$ & $(0 ; 0.1 ; 0.2)$ \\
\hline$x_{13}$ & 0,0667 & $(0.6 ; 0.5 ; 0.4)$ & $(0.2 ; 0.1 ; 0)$ & $(0.2 ; 0.1 ; 0)$ \\
\hline$x_{14}$ & 0,0667 & $(0.6 ; 0.5 ; 0.4)$ & $(0.2 ; 0.1 ; 0)$ & $(0.2 ; 0.1 ; 0)$ \\
\hline$x_{15}$ & 0,0667 & $(0.6 ; 0.7 ; 0.8)$ & $(0.6 ; 0.7 ; 0.8)$ & $(0.4 ; 0.5 ; 0.6)$ \\
\hline \multicolumn{5}{|c|}{ 'Buffer' areas } \\
\hline$x_{1}$ & 0,0553 & $(30.4 ; 40.0 ; 48.2)$ & $(30.4 ; 40.0 ; 48.2)$ & $(30.4 ; 40.0 ; 48.2)$ \\
\hline$x_{2}$ & 0,0567 & $(32.9 ; 30.3 ; 26.8)$ & $(32.9 ; 30.3 ; 26.8)$ & $(32.9 ; 30.3 ; 26.8)$ \\
\hline$x_{3}$ & 0,0833 & $(47.3 ; 55.8 ; 61.2)$ & $(47.3 ; 55.8 ; 61.2)$ & $(47.3 ; 55.8 ; 61.2)$ \\
\hline$x_{4}$ & 0,0553 & $(59.9 ; 78.1 ; 97.8)$ & $(59.9 ; 78.1 ; 97.8)$ & $(59.9 ; 78.1 ; 97.8)$ \\
\hline$x_{5}$ & 0,0747 & $(356.5 ; 663.5 ; 1398.6)$ & $(356.5 ; 663.5 ; 1398.6)$ & $(356.5 ; 663.5 ; 1398.6)$ \\
\hline$x_{6}$ & 0,0747 & $(0.41 ; 244.0 ; 607.8)$ & $(0.41 ; 244.0 ; 607.8)$ & $(0.41 ; 244.0 ; 607.8)$ \\
\hline$x_{7}$ & 0,0667 & $(808.6 ; 288.8 ; 37.6)$ & $(121.3 ; 62.7 ; 30.1)$ & $(21.3 ; 15.2 ; 9.1)$ \\
\hline$x_{8}$ & 0,0667 & $(32.8 ; 73.0 ; 255.4)$ & $(8.2 ; 27.4 ; 51.1)$ & $(0.3 ; 0.5 ; 1.3)$ \\
\hline
\end{tabular}


Continued Table 7

\begin{tabular}{ccccc}
\hline $\begin{array}{c}\text { Criteria } \\
\text { (indicator) }\end{array}$ & $\begin{array}{l}\text { Weight of } \\
\text { indicator }\end{array}$ & Alternative $A^{1}$ & Alternative $A^{2}$ & Alternative $A^{3}$ \\
\hline \multicolumn{5}{c}{ 'Buffer' areas } \\
\hline$x_{9}$ & 0,0667 & $(14.4 ; 85.5 ; 239.3)$ & $(4.1 ; 13.7 ; 28.7)$ & $(0 ; 0 ; 0)$ \\
\hline$x_{10}$ & 0,0667 & $(23.0 ; 3.8 ; 10.6)$ & $(0.6 ; 1.9 ; 2.7)$ & $(0 ; 0 ; 0)$ \\
\hline$x_{11}$ & 0,0667 & $(9.1 ; 26.6 ; 53.2)$ & $(2.3 ; 5.7 ; 10.6)$ & $(0.1 ; 0.2 ; 0.5)$ \\
\hline$x_{12}$ & 0,0667 & $(0.4 ; 0.5 ; 0.6)$ & $(0.2 ; 0.3 ; 0.4)$ & $(0.2 ; 0.3 ; 0.4)$ \\
\hline$x_{13}$ & 0,0667 & $(1 ; 0.9 ; 0.8)$ & $(0.2 ; 0.1 ; 0)$ & $(0.6 ; 0.5 ; 0.4)$ \\
\hline$x_{14}$ & 0,0667 & $(0.4 ; 0.3 ; 0.2)$ & $(0.2 ; 0.1 ; 0)$ & $(0.2 ; 0.1 ; 0)$ \\
\hline$x_{15}$ & 0,0667 & $(0.8 ; 0.9 ; 1)$ & $(0.4 ; 0.5 ; 0.6)$ & $(0.8 ; 0.9 ; 1)$ \\
\hline
\end{tabular}

The construction of triangular fuzzy numbers $\mu_{j}=\left(\mu_{j, L}, \mu_{j, M}, \mu_{j, U}\right)$, according to formulas (12) and (13), could be done as follows: indicator $x_{1}$ - average soil fertility in the area measured in points is given by 9 fuzzy numbers $(30.9 ; 39.9 ; 50.0),(30.9 ; 39.9 ; 50.0)$, $(30.9 ; 39.9 ; 50.0),(31.1 ; 34.8 ; 44.3),(31.1 ; 34.8 ; 44.3),(31.1 ; 34.8 ; 44.3),(30.4 ; 40.0 ; 48.2)$, (30.4; 40.0;48.2), (30.4; 40.0;48.2).

Let's choose $m_{1}=\min _{i} x_{1, L}^{i}=30.4, M_{1}=\max _{i} x_{1, U}^{i}=50 . x_{1}$ has a direct relationship with the alternatives (a greater value is better). Thus, following the application of formula (12), normalized triangular fuzzy numbers values $(0.0255 ; 0.4846 ; 1.0),(0.0255 ; 0.4846 ; 1.0)$, (0.0255; 0.4846; 1.0), (0.0357; 0.2245; 0.7092), (0.0357; 0.2245; 0.7092), (0.0357; 0.2245; $0.7092),(0.0 ; 0.4898 ; 0.9082),(0.0 ; 0.4898 ; 0.9082),(0.0 ; 0.4898 ; 0.9082)$ are obtained.

Variable $x_{2}$ - the quality of life of the local population measured in points has an opposite relationship with the alternatives (a lower value is better). $m_{2}=\min _{i} x_{2, L}^{i}=20.78$, $M_{2}=\max _{i} x_{2, U}^{i}=39.3$ are chosen and, according to formula (13), normalized values having a direct relationship with the alternatives $(0 . ; 0.4104 ; 0.8747),(0 . ; 0.4104 ; 0.8747),(0 . ; 0.4104$; 0.8747), (0.0821;0.5508; 1.0), (0.0821; 0.5508; 1.0), (0.0821;0.5508; 1.0), (0.3456; 0.486; $0.6749)$, (0.3456; $0.486 ; 0.6749),(0.3456 ; 0.486 ; 0.6749)$ are calculated.

$x_{3}$ - population activity index (\%) and lower and upper theoretical bounds of indicator $x_{3}$ are $m_{3}=0, M_{3}=100$. After transformation, all calculated normalized fuzzy variables have a direct relationship with alternatives $A^{1}, A^{2}, A^{3}$.

Next, intuitionistic fuzzy numbers by the generation of $v_{j}^{i}=\left(v_{j, L}^{i}, v_{j, M}^{i}, v_{j, U}^{i}\right)$ - lower, modal and upper degrees of the non-adequacy of alternative $A^{i}$ to indicator (criteria) $x_{j}$ are constructed. Non-adequacy values have either normal distribution with an average equal to 0.1 or zero values in case $\mu_{j, U}^{i}=1$. From the definition of intuitionistic fuzzy numbers, inequalities $0 \leq v_{j, L}^{i}, v_{j, M}^{i}, v_{j, U}^{i} \leq 1, \mu_{j, U}^{i}+v_{j, U}^{i} \leq 1$ must be hold. Table 8 presents intuitionistic fuzzy numbers of the decision matrix of an active development area. In the same manner, the decision matrixes of regressing development and 'buffer' areas have been created.

For every column of the decision matrix given in Table 8 containing information about project $i, 5$ weighted generalized average operators $I_{i}^{p}, p=0.0 ; 0.01 ; 0.5 ; 1.0 ; 2.0$ are calculated referring to formula (11) so that to aggregate all elements associated with project $i$. 
Table 8. Intuitionistic fuzzy numbers constructed from the initial decision matrix of an active development area

\begin{tabular}{|c|c|c|c|}
\hline $\begin{array}{c}\text { Criteria } \\
\text { (indicator) }\end{array}$ & Alternative $A^{1}$ & Alternative $A^{2}$ & Alternative $A^{3}$ \\
\hline$x_{1}$ & $([0.0255 ; 0.4846 ; 1] ;[0 ; 0 ; 0])$ & $([0.0255 ; 0.4846 ; 1] ;[0 ; 0 ; 0])$ & $([0.0255 ; 0.4846 ; 1] ;[0 ; 0 ; 0])$ \\
\hline$x_{2}$ & $\begin{array}{l}([0 ; 0.4103 ; 0.8747] ; \\
[0.0652 ; 0.0952 ; 0.1252])\end{array}$ & $\begin{array}{l}([0 ; 0.4103 ; 0.8747] ; \\
[0.0652 ; 0.0952 ; 0.1252])\end{array}$ & $\begin{array}{l}([0 ; 0.4103 ; 0.8747] ; \\
[0.0652 ; 0.0952 ; 0.1252])\end{array}$ \\
\hline$x_{3}$ & $\begin{array}{l}([0.398 ; 0.517 ; 0.681] ; \\
[0 ; 0.0188 ; 0.0488])\end{array}$ & $\begin{array}{l}([0.398 ; 0.517 ; 0.681] ; \\
[0 ; 0.0188 ; 0.0488])\end{array}$ & $\begin{array}{l}([0.398 ; 0.517 ; 0.681] ; \\
[0 ; 0.0188 ; 0.0488])\end{array}$ \\
\hline$x_{4}$ & $([0.1808 ; 0.4974 ; 1] ;[0 ; 0 ; 0])$ & $([0.1808 ; 0.4974 ; 1] ;[0 ; 0 ; 0])$ & $([0.1808 ; 0.4974 ; 1] ;[0 ; 0 ; 0])$ \\
\hline$x_{5}$ & $([0.1015 ; 0.3260 ; 1] ;[0 ; 0 ; 0])$ & $([0.1015 ; 0.3260 ; 1] ;[0 ; 0 ; 0])$ & $([0.1015 ; 0.3260 ; 1] ;[0 ; 0 ; 0])$ \\
\hline$x_{6}$ & $([0.0174 ; 0.2472 ; 1] ;[0 ; 0 ; 0])$ & $([0.0174 ; 0.2472 ; 1] ;[0 ; 0 ; 0])$ & $([0.0174 ; 0.2472 ; 1] ;[0 ; 0 ; 0])$ \\
\hline$x_{7}$ & $\begin{array}{l}([0.0530 ; 0.6679 ; 0.9650] \\
[0 ; 0.0049 ; 0.0349])\end{array}$ & $\begin{array}{l}([0.8285 ; 0.9353 ; 0.9739] ; \\
[0 ; 0 ; 0.0260])\end{array}$ & $\begin{array}{l}([0.9842 ; 0.9915 ; 0.9987] ; \\
[0 ; 0 ; 0.0012])\end{array}$ \\
\hline$x_{8}$ & $\begin{array}{l}([0.1210 ; 0.2699 ; 0.9471] ; \\
[0 ; 0.0228 ; 0.0528])\end{array}$ & $\begin{array}{l}([0.0297 ; 0.1007 ; 0.1888] ; \\
[0.1007 ; 0.1307 ; 0.1607])\end{array}$ & $\begin{array}{l}([0.0003 ; 0.0007 ; 0.0039] ; \\
[0.0124 ; 0.0424 ; 0.0724])\end{array}$ \\
\hline$x_{9}$ & $\begin{array}{l}([0.0096 ; 0.0585 ; 0.1633] ; \\
[0 ; 0.0178 ; 0.0478])\end{array}$ & $\begin{array}{l}([0.0029 ; 0.0091 ; 0.0196] ; \\
[0 ; 0 ; 0.0118])\end{array}$ & $\begin{array}{l}([0 ; 0 ; 0] ; \\
[0.0646 ; 0.0946 ; 0.1246])\end{array}$ \\
\hline$x_{10}$ & $\begin{array}{l}([0.1981 ; 0.3207 ; 0.9056] \\
[0.0343 ; 0.0643 ; 0.0943])\end{array}$ & $\begin{array}{l}([0.0471 ; 0.1603 ; 0.2264] ; \\
[0.0513 ; 0.0813 ; 0.1113])\end{array}$ & $\begin{array}{l}([0 ; 0 ; 0] ; \\
[0.1162 ; 0.1462 ; 0.1762])\end{array}$ \\
\hline$x_{11}$ & $\begin{array}{l}([0.1600 ; 0.4048 ; 0.9472] ; \\
[0 ; 0.0227 ; 0.0527])\end{array}$ & $\begin{array}{l}([0.0395 ; 0.0998 ; 0.1883] ; \\
[0.0020 ; 0.0320 ; 0.0620])\end{array}$ & $\begin{array}{l}([0 ; 0.0018 ; 0.0075] ; \\
[0.0438 ; 0.0738 ; 0.1038])\end{array}$ \\
\hline$x_{12}$ & $\begin{array}{l}([0.8 ; 0.9 ; 1] ; \\
[0 ; 0 ; 0])\end{array}$ & $\begin{array}{l}([0.2 ; 0.3 ; 0.4] ; \\
[0 ; 0.0239 ; 0.0539])\end{array}$ & $\begin{array}{l}([0.6 ; 0.7 ; 0.8] ; \\
[0 ; 0.0191 ; 0.0491])\end{array}$ \\
\hline$x_{13}$ & $\begin{array}{l}([0 ; 0.1 ; 0.2] ; \\
[0 ; 0.0036 ; 0.0336])\end{array}$ & $\begin{array}{l}([0.8 ; 0.9 ; 1] ; \\
[0 ; 0 ; 0])\end{array}$ & $\begin{array}{l}([0.2 ; 0.3 ; 0.4] ; \\
[0.1080 ; 0.1380 ; 0.1680])\end{array}$ \\
\hline$x_{14}$ & $\begin{array}{l}([0 ; 0.125 ; 0.25] ; \\
[0.1023 ; 0.1323 ; 0.1623]) \\
\end{array}$ & $\begin{array}{l}([0.25 ; 0.375 ; 0.5] ; \\
[0.1385 ; 0.1685 ; 0.1985]) \\
\end{array}$ & $\begin{array}{l}([0.75 ; 0.875 ; 1] ; \\
[0 ; 0 ; 0])\end{array}$ \\
\hline$x_{15}$ & $\begin{array}{l}([0.5 ; 0.625 ; 0.75] ; \\
[0.0123 ; 0.0423 ; 0.0723])\end{array}$ & $\begin{array}{l}([0.25 ; 0.375 ; 0.5] ; \\
[0.0501 ; 0.0801 ; 0.1101])\end{array}$ & $\begin{array}{l}([0 ; 0.125 ; 0.25] ; \\
[0.0588 ; 0.0888 ; 0.1188])\end{array}$ \\
\hline
\end{tabular}

Notice that if $p=1.0, I_{i}^{1}$ is the weighted arithmetic averaging operator, and if $p=0.0$, $I_{i}^{0}$ is the weighted geometric averaging operator. Then, for each $p$, the values of the score function are calculated using formulas (5)-(7) and ranking intuitionistic fuzzy numbers is accomplished. The results are given in Table 9. Additionally, the ranking results obtained after applying 4 FMCDM methods - COPRAS, TOPSIS, including vector and linear normalization and VIKOR (Antuchevičienè et al. 2011) are presented in Table 9. The ranking results of active development areas differ depending on the applied method. COPRAS, TOPSIS with linear normalization and VIKOR rank the alternatives in the following order: $A^{2} \succ A^{1} \succ A^{3}$. The method of generalized aggregated fuzzy average functions gives similar results of intuitionistic interval values and $p=0.01\left(A^{2} \succ A^{1} \approx A^{3}\right)$ and intuitionistic point values and $p=0.01$ $\left(A^{2} \approx A^{1} \succ A^{3}\right)$. Triangular, interval and point generalized average methods with $p=0.0 ; 0.5$; $1.0 ; 2$ give another best alternatives as well as intuitionistic triangular values for $p=0.01$.

For the areas of regressing development, COPRAS and TOPSIS with linear normalization rank the alternatives in the order of $A^{2} \succ A^{3} \approx A^{1}$, VIKOR $-A^{2} \succ A^{3} \succ A^{1}$, TOPSIS with vector normalization $-A^{2} \succ A^{1} \succ A^{3}$. Closest to the introduced results are all generalized aggregated fuzzy average functions with $p=0.01 ; 0.5$, except a triangular value for $p=0.01$. 
Difficulties in making some strict inferences in the case of ranking results of 'buffer' areas appear, because the results differ not only in different $\mathrm{p}$ values taking into account the method of generalized aggregated fuzzy average functions, but also considering various FMCDM methods. Nevertheless, only generalized aggregated fuzzy average functions having $p=0$ (geometric mean) ranking results coincide with ranking results of COPRAS and TOPSIS using vector normalization: $A^{1} \succ A^{2} \succ A^{3}$.

Table 9. Ranking results of the areas of active development

\begin{tabular}{|c|c|c|c|c|}
\hline \multicolumn{5}{|c|}{ Areas of active development } \\
\hline \multirow{2}{*}{ Method } & \multicolumn{3}{|c|}{ Scores of alternatives } & \multirow{2}{*}{ Priority order } \\
\hline & $A^{1}$ & $A^{2}$ & $A^{3}$ & \\
\hline Triangular $p=0$ & 0.2949 & 0.1879 & -0.0371 & $A^{1} \succ A^{2} \succ A^{3}$ \\
\hline Interval $p=0$ & 0.2996 & 0.1754 & -0.0372 & $A^{1} \succ A^{2} \succ A^{3}$ \\
\hline Point $p=0$ & 0.2856 & 0.2129 & -0.0369 & $A^{1} \succ A^{2} \succ A^{3}$ \\
\hline Triangular $p=0.01$ & 0.4771 & 0.5067 & 0.6476 & $A^{3} \succ A^{2} \succ A^{1}$ \\
\hline Interval $p=0.01$ & 0.5094 & 0.5538 & 0.5037 & $A^{2} \succ A^{1} \approx A^{3}$ \\
\hline Point $p=0.01$ & 0.4124 & 0.4125 & 0.2404 & $A^{2} \approx A^{1} \succ A^{3}$ \\
\hline Triangular $p=0.5$ & 0.5319 & 0.5589 & 0.5851 & $A^{3} \succ A^{2} \succ A^{1}$ \\
\hline Interval $p=0.5$ & 0.5803 & 0.6128 & 0.6395 & $A^{3} \succ A^{2} \succ A^{1}$ \\
\hline Point $p=0.5$ & 0.4351 & 0.4512 & 0.4763 & $A^{3} \succ A^{2} \succ A^{1}$ \\
\hline Triangular $p=1$ & 0.5607 & 0.5935 & 0.6476 & $A^{3} \succ A^{2} \succ A^{1}$ \\
\hline Interval $p=1$ & 0.6118 & 0.6464 & 0.6984 & $A^{3} \succ A^{2} \succ A^{1}$ \\
\hline Point $p=1$ & 0.4587 & 0.4877 & 0.546 & $A^{3} \succ A^{2} \succ A^{1}$ \\
\hline Triangular $p=2$ & 0.6078 & 0.6496 & 0.7206 & $A^{3} \succ A^{2} \succ A^{1}$ \\
\hline Interval $p=2$ & 0.6604 & 0.6991 & 0.7666 & $A^{3} \succ A^{2} \succ A^{1}$ \\
\hline Point $p=2$ & 0.5027 & 0.5504 & 0.6287 & $A^{3} \succ A^{2} \succ A^{1}$ \\
\hline COPRAS & & & & $A^{2} \approx A^{1} \succ A^{3}$ \\
\hline TOPSIS (vector normalization) & & & & $A^{1} \succ A^{2} \succ A^{3}$ \\
\hline TOPSIS (linear normalization) & & & & $A^{2} \succ A^{1} \succ A^{3}$ \\
\hline VIKOR & & & & $A^{2} \succ A^{1} \succ A^{3}$ \\
\hline \multicolumn{5}{|c|}{ Areas of regressing development } \\
\hline \multirow{2}{*}{ Method } & \multicolumn{3}{|c|}{ Scores of alternatives } & \multirow{2}{*}{ Priority order } \\
\hline & $A^{1}$ & $A^{2}$ & $A^{3}$ & \\
\hline Triangular $p=0$ & 0.3196 & 0.2189 & -0.061 & $A^{1} \succ A^{2} \succ A^{3}$ \\
\hline Interval $p=0$ & 0.3247 & 0.2081 & -0.061 & $A^{1} \succ A^{2} \succ A^{3}$ \\
\hline Point $p=0$ & 0.3095 & 0.2406 & -0.061 & $A^{1} \succ A^{2} \succ A^{3}$ \\
\hline Triangular $p=0.01$ & 0.495 & 0.5466 & 0.6715 & $A^{3} \succ A^{2} \succ A^{1}$ \\
\hline Interval $p=0.01$ & 0.5443 & 0.5813 & 0.5019 & $A^{2} \succ A^{1} \succ A^{3}$ \\
\hline Point $p=0.01$ & 0.3965 & 0.4773 & 0.2564 & $A^{2} \succ A^{1} \succ A^{3}$ \\
\hline Triangular $p=0.5$ & 0.5252 & 0.6107 & 0.6052 & $A^{2} \succ A^{3} \succ A^{1}$ \\
\hline Interval $p=0.5$ & 0.5853 & 0.6574 & 0.6573 & $A^{2} \approx A^{3} \succ A^{1}$ \\
\hline Point $p=0.5$ & 0.405 & 0.5171 & 0.5012 & $A^{2} \succ A^{3} \succ A^{1}$ \\
\hline Triangular $p=1$ & 0.5389 & 0.6491 & 0.6715 & $A^{3} \succ A^{2} \succ A^{1}$ \\
\hline Interval $p=1$ & 0.6008 & 0.6959 & 0.7192 & $A^{3} \succ A^{2} \succ A^{1}$ \\
\hline Point $p=1$ & 0.4153 & 0.5555 & 0.5763 & $A^{3} \succ A^{2} \succ A^{1}$ \\
\hline
\end{tabular}


Continued Table 9

\begin{tabular}{|c|c|c|c|c|}
\hline \multicolumn{5}{|c|}{ Areas of regressing development } \\
\hline \multirow{2}{*}{ Method } & \multicolumn{3}{|c|}{ Scores of alternatives } & \multirow{2}{*}{ Priority order } \\
\hline & $A^{1}$ & $A^{2}$ & $A^{3}$ & \\
\hline Triangular $p=2$ & 0.5623 & 0.703 & 0.7448 & $A^{3} \succ A^{2} \succ A^{1}$ \\
\hline Interval $p=2$ & 0.6245 & 0.7456 & 0.7854 & $A^{3} \succ A^{2} \succ A^{1}$ \\
\hline Point $p=2$ & 0.4379 & 0.6177 & 0.6636 & $A^{3} \succ A^{2} \succ A^{1}$ \\
\hline COPRAS & & & & $A^{2} \succ A^{3} \approx A^{1}$ \\
\hline TOPSIS (vector normalization) & & & & $A^{2} \succ A^{1} \succ A^{3}$ \\
\hline TOPSIS (linear normalization) & & & & $A^{2} \succ A^{3} \approx A^{1}$ \\
\hline VIKOR & & & & $A^{2} \succ A^{3} \succ A^{1}$ \\
\hline \multicolumn{5}{|c|}{ 'Buffer' areas } \\
\hline \multirow{2}{*}{ Method } & \multicolumn{3}{|c|}{ Scores of alternatives } & \multirow{2}{*}{ Priority order } \\
\hline & $A^{1}$ & $A^{2}$ & $A^{3}$ & \\
\hline Triangular $p=0$ & 0.2486 & 0.1699 & -0.0485 & $A^{1} \succ A^{2} \succ A^{3}$ \\
\hline Interval $p=0$ & 0.2399 & 0.1507 & -0.0489 & $A^{1} \succ A^{2} \succ A^{3}$ \\
\hline Point $p=0$ & 0.2659 & 0.2083 & -0.0477 & $A^{1} \succ A^{2} \succ A^{3}$ \\
\hline Triangular $p=0.01$ & 0.4763 & 0.499 & 0.6692 & $A^{3} \succ A^{2} \succ A^{1}$ \\
\hline Interval $p=0.01$ & 0.5034 & 0.5336 & 0.5038 & $A^{2} \succ A^{3} \succ A^{1}$ \\
\hline Point $p=0.01$ & 0.4221 & 0.43 & 0.2452 & $A^{2} \succ A^{1} \succ A^{3}$ \\
\hline Triangular $p=0.5$ & 0.5462 & 0.5867 & 0.6069 & $A^{3} \succ A^{2} \succ A^{1}$ \\
\hline Interval $p=0.5$ & 0.5972 & 0.6426 & 0.6657 & $A^{3} \succ A^{2} \succ A^{1}$ \\
\hline Point $p=0.5$ & 0.4441 & 0.4747 & 0.4893 & $A^{3} \succ A^{2} \succ A^{1}$ \\
\hline Triangular $p=1$ & 0.5754 & 0.6279 & 0.6692 & $A^{3} \succ A^{2} \succ A^{1}$ \\
\hline Interval $p=1$ & 0.63 & 0.6826 & 0.7216 & $A^{3} \succ A^{2} \succ A^{1}$ \\
\hline Point $p=1$ & 0.4662 & 0.5185 & 0.5644 & $A^{3} \succ A^{2} \succ A^{1}$ \\
\hline Triangular $p=2$ & 0.6154 & 0.6863 & 0.7373 & $A^{3} \succ A^{2} \succ A^{1}$ \\
\hline Interval $p=2$ & 0.6702 & 0.7343 & 0.7807 & $A^{3} \succ A^{2} \succ A^{1}$ \\
\hline Point $p=2$ & 0.5057 & 0.5904 & 0.6503 & $A^{3} \succ A^{2} \succ A^{1}$ \\
\hline COPRAS & & & & $A^{1} \succ A^{2} \succ A^{3}$ \\
\hline TOPSIS (vector normalization) & & & & $A^{1} \succ A^{2} \succ A^{3}$ \\
\hline TOPSIS (linear normalization) & & & & $A^{3} \succ A^{1} \succ A^{2}$ \\
\hline VIKOR & & & & $A^{3} \succ A^{1} \succ A^{2}$ \\
\hline
\end{tabular}

Notice, that for $p=0$ (geometric mean), the scores of alternative $A^{3}$ for active development areas, the areas of regressing development and 'buffer' areas are negative while the scores of other alternatives are positive. Thus, alternative $A^{3}$ will always be the worst. Such situation of a geometric mean will be in the case when for at least one of indicators $\mu_{j}=(0,0,0)$ for the given alternative. Therefore, we have $\mu_{9}=(0,0,0)$ and $\mu_{10}=(0,0,0)$ for $x_{9}$ and $x_{10}$ (see Table 7). Suppose that for one alternative and at least one variable $x_{j}: \mu_{j, U}=1$; then, $v_{j, U}=0$ and $v_{j}=(0,0,0)$. In this case, the values of the generalized aggregated fuzzy average function are not intuitionistic fuzzy numbers because $v_{I^{p}}=(0,0,0)$ for all $\mathrm{p}$, except $p=0$. Table 8 shows such variables $\left(x_{4}, x_{5}, x_{6}\right)$ for each of 3 alternatives, i.e. the values of the generalized aggregated fuzzy average function for $p \neq 0$ are simple triangular fuzzy numbers (not intuitionistic fuzzy numbers) for all 3 alternatives. 


\section{Conclusions}

The following conclusions from ranking alternatives on the basis of generalized aggregated fuzzy average functions could be derived:

1. Ranking results of active development areas are closest to the results given employing COPRAS, TOPSIS and VIKOR methods when $p=0.01$ and using intuitionistic interval values or intuitionistic point values.

2. Ranking results of regressing development areas are closest to the results given applying COPRAS, TOPSIS and VIKOR methods when $p=0.01 ; 0.5$, except triangular value for $p=0.01$.

3. The method of generalized aggregated average fuzzy functions does not properly discriminate alternatives when $\mathrm{p}=1,2$. These functions are not sensitive enough. Thus, an arithmetic average $(p=1)$ is not the best method for ranking alternatives.

4. When for at least one of indicators (criteria) and one alternative $\mu_{j}=(0,0,0)$, the geometric aggregated fuzzy average function $(p=0)$ is not a reasonable method for FMCDM, as despite of the values of the other criteria, this alternative will be the worst.

5. When for at least one of indicators (criteria) and one alternative $\mu_{j}=(1,1,1)$, the arithmetic aggregated fuzzy average function $(p=1)$ is not reasonable method for FMCDM, as despite of the values of the other criteria, this alternative will be the best.

These results confirm similar conclusions drawn by the Monte Carlo experiment. The lowest values of ranking errors in the case of generating uniform distribution included interval generalized averaging operators having exponents $p=0.01$ and $p=0.25$ and triangular generalized averaging operators when $p=0.01$. The lowest values of ranking errors in the case of generating normal distribution were those of point generalized averaging operators having exponents $p=0.01$ and $p=0.25$. Notice that in the case of normal distribution, the application of interval and triangular intuitionistic fuzzy numbers does not improve the results. Other remark is that neither arithmetic nor geometric averaging operators provided the lowest values of ranking errors.

\section{Acknowledgment}

The authors sincerely thank J. Antucheviciene, A. Zakarevicius and E. Zavadskas for providing data on researching a problem of ranking possible redevelopment alternatives of derelict rural buildings.

\section{References}

Antuchevičienė, J.; Zakarevičius, A.; Zavadskas, E. K. 2011. Measuring congruence of ranking results applying particular MCDM methods, Informatica 22(3): 319-338.

Antuchevičienė, J.; Zavadskas, E. K.; Zakarevičius, A. 2010. Multiple criteria construction management decisions considering relations between criteria, Technological and Economic Development of Economy 16(1): 109-125. http://dx.doi.org/10.3846/tede.2010.07 
Atanassov, K. 1986. Intuitionistic fuzzy sets, Fuzzy Sets and Systems 20(1): 87-96. http://dx.doi.org/10.1016/S0165-0114(86)80034-3

Atanassov, K.; Gargov, G. 1989. Interval valued intuitionistic fuzzy sets, Fuzzy Sets and Systems 31(3): 343-349. http://dx.doi.org/10.1016/0165-0114(89)90205-4

Burillo, P.; Bustince, H.; Mohedano, V. 1994. Some definition of intuitionistic fuzzy number, in Fuzzy based expert systems, fuzzy Bulgarian enthusiasts, 28-30 September 1994, Sofia, Bulgaria.

Bustince, H.; Burillo, P. 1995. A theorem for constructing interval-valued intuitionistic fuzzy sets from intuitionistic fuzzy sets, Notes on IFS 1(1): 5-16.

Chen, S. M.; Tan, J. M. 1994. Handling multi-criteria fuzzy decision-making problems based on vague set theory, Fuzzy Sets and Systems 67: 163-172. http://dx.doi.org/10.1016/0165-0114(94)90084-1

Deng, H.-P. 2009. Developments in fuzzy multicriteria analysis, Fuzzy Information and Engineering 1(1): 103-109. http://dx.doi.org/10.1007/s12543-009-0008-y

Dubois, D.; Gottwald, S.; Hajek, P.; Kacprzyk, J.; Prade, H. 2005. Terminological difficulties in fuzzy set theory-the case of "Intuitionistic Fuzzy Sets", Fuzzy Sets and Systems 156: 485-491.

http://dx.doi.org/10.1016/j.fss.2005.06.001

Figueira, J.; Greco, S.; Ehrgott, M. 2005. Multiple criteria decision analysis: state of the art surveys. Springer, New York.

Han, Z.; Liu, P. 2011. A fuzzy multi-atribute decision-making method under risk with unknown attribute weights, Technological and Economic Development of Economy 17(2): 246-258. http://dx.doi.org/10.3846/20294913.2011.580575

Hong, D. J.; Choi, C. H. 2000. Multi-criteria fuzzy decision-making problems based on vague set theory, Fuzzy Sets and Systems 114: 103-113. http://dx.doi.org/10.1016/S0165-0114(98)00271-1

Hwang, C. L.; Yoon, K. 1981. Multiple attribute decision making: a state of the art survey, in Lecture Notes in Economics and Mathematical Systems 186, Berlin: Springer-Verlag.

Gentle, J. E. 2003. Random Number Generation and Monte Carlo Methods. $2^{\text {nd }}$ ed. New York: Springer.

Liu, P. 2009. Multi-attribute decision-making method research based on interval vague set and TOPSIS method, Technological and Economic Development of Economy 15(3): 453-463. http://dx.doi.org/10.3846/1392-8619.2009.15.453-463

Merigo, J. M.; Wei, G. 2011. Probabilistic aggregation operators and their application in uncertain multiperson decision-making, Technological and Economic Development of Economy 17(2): 335-351. http://dx.doi.org/10.3846/20294913.2011.584961

Wei, G.; Zhao, X.; Wang, H. 2012. An approach to multiple attribute group decision making with interval intuitionistic trapezoidal fuzzy information, Technological and Economic Development of Economy 18(2): 317-330. http://dx.doi.org/10.3846/20294913.2012.676995

Xu, Z. 2007a. Intuitionistic fuzzy aggregation operators, IEEE Transations on Fuzzy Systems 15(6): 1179-1187. http://dx.doi.org/10.1109/TFUZZ.2006.890678

$\mathrm{Xu}, \mathrm{Z} .2007 \mathrm{~b}$. Methods for aggregating interval-valued intuitionistic fuzzy information and their application to decision making, Control and Decision 22(2): 215-219.

Yager, R. R. 1988. On ordered weighted averaging aggregation operators in multi-criteria decision making, IEEE Transactions on Systems, Man and Cybernetics 18(1): 183-190. http://dx.doi.org/10.1109/21.87068

Zavadskas, E. K.; Turskis, Z. 2011. Multiple criteria decision making (MCDM) methods in economics: an overview, Technological and Economic Development of Economy 17(2): 397-427. http://dx.doi.org/10.3846/20294913.2011.593291

Zhang, X.; Liu, P. 2010. Method for aggregating triangular fuzzy intuitionistic fuzzy information and its application to decision making, Technological and Economic Development of Economy 16(2): 280-290. http://dx.doi.org/10.3846/tede.2010.18 
Zhao, H.; Xu, Z. S.; Ni, M.; Liu, S. 2010. Generalized aggregation operators for intuitionistic fuzzy sets, International Journal of Intelligent Systems 25(1): 1-30. http://dx.doi.org/10.1002/int.20386

Zadeh, L. 1965. Fuzzy sets, Information and Control 8: 338-353. http://dx.doi.org/10.1016/S00199958(65)90241-X

Zanakis, S. H.; Solomon, A.; Wishart, N.; Dublish, S. 1998. Multi-attribute decision making: a simulation comparison of select methods, European Journal of Operational Research 107: 507-529. http://dx.doi.org/10.1016/S0377-2217(97)00147-1

Zimmermann, H. J. 1985. Fuzzy set theory and its applications. Dordrecht: Kluwer Academic.

Natalja KOSAREVA. Assoc. Prof., Dr at the Department of Mathematical Modelling, Vilnius Gediminas Technical University (VGTU). Doctor of Mathematics (1986). Research interests: mathematical modelling, fuzzy sets, mathematical statistics in education, information technologies.

Aleksandras KRYLOVAS. Prof., Dr (HP), the Head of the Department of Mathematical Modelling, Mykolas Romeris University (MRU). Doctor of Mathematics (1987), (HP - 2006). Research interests: mathematical modelling, fuzzy sets, asymptotic analysis, didactics of mathematics. 